


\section{To Illinois Junior Citizens In Cities and Towns... .}

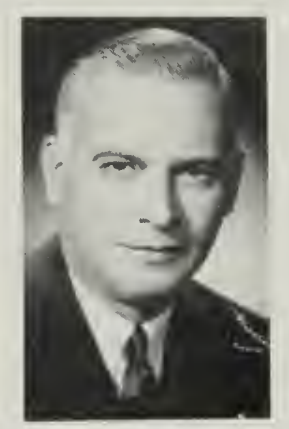

OU have the opportunity to render a patriotic service that
has not come to many boys and girls of past generations.
American farmers have been asked to grow more food and fiber in 1943 than they have ever before produced even in years of the most bountiful harvests. If we fail to meet the rapidly increasing demands of our armies, our civilian workers, our allies, and the liberated peoples for these essential war materials, the whole war effort will be handicapped and thousands of lives lost that could have been saved.

Illinois farmers can do their share in this great effort only if large numbers of able and willing farm workers are found to replace the thousands who have left our farms to enter the armed forces and essential war industries. This is where strong, interested, intelligent city boys and girls can make a truly important contribution to our war effort.

To those of you who are willing and able to enter service on our farms, I commend this booklet. It has been written especially for you by members of the staff of the College of Agriculture of your State University-men who have grown up on farms, have studied farm life, and know the problems young people will meet on farms. It has been issued by the Illinois State Council of Defense. It will help you to get acquainted with what lies before you and prepare for it. Study it thoroughly and take to heart all the advice you find there.

The State of Illinois, your country, and the hungry people of Europe will recognize and be grateful for your help.

SPringfield, Illinois

JANUARY, 1943

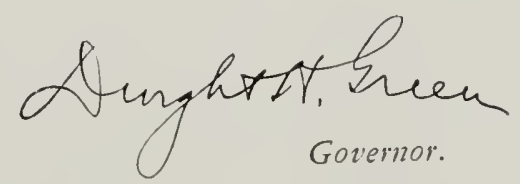




\section{Prepared by \\ COLLEGE OF AGRICULTURE UNIVERSITY OF ILLINOIS}

\section{$\star$ \\ Issued by \\ ILLINOIS STATE COUNCIL OF DEFENSE}

Gov. Dwight H. Green, Chaiman Frank O. Lowden, Honorary Chairman

Murray M. Baker, Vice Chairman

Lieut. Gov. Hugh W. Cross, Secretary

Speaker Elmer J. Schnackenberg, Treasurer

Sen. Arnold P. Benson

Rep. Reed F. Cutler

Sen. Richard J. Daley

STUART DUNCAN

Rev. James L. Horace

HENRY P. RUSK
Reuben G. Soderstrom

BARNEY THOMPSON

Charles M. Thompson

Mrs. Frederic W. Upham

Rep. Bernice T. Van der Vries

ReP. William Vicars 


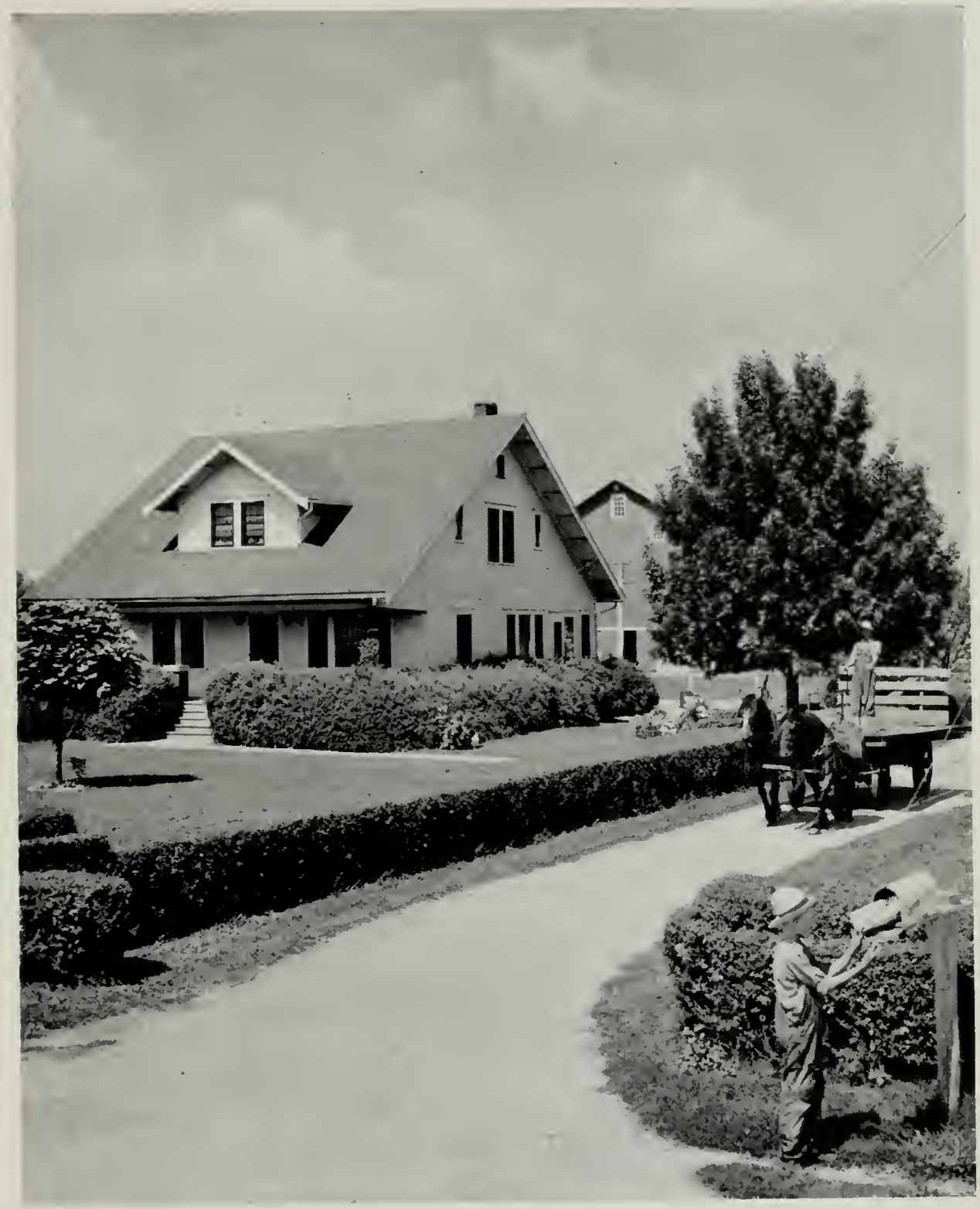

The farm is a home as well as a place of business. This family enjoys an attractive house and a well-kept lawn. The livestock are housed in the barn in the rear. The farmer is on the way to the field with a rack wagon, while his son gets the mail left by the rural mail carrier. 


\section{Why City Boys and Girls Are Needed on Farms in 1943}

\section{Your Part in the War Effort}

Right now you and all persons in the United States are being called upon to contribute your utmost to the war effort. Let's stop and take inventory. Just what specific things have you done to help defeat the Axis Powers?

If your school has been active in the scrap, rubber, and other salvage drives, you have no doubt contributed some time and effort in helping collect these precious war materials. Many of you are defense bond holders, or save a large share of your allowance or earnings for defense stamps. These and other contributions are important-but, are they enough? If we are to exterminate fascism and its brutal, undemocratic forces from the face of this earth, we have a fight on our hands that requires an allout effort on the part of every citizen in our country. Each individual must contribute his time and abilities to the fullest extent.

Of course, at the present, your proper place is in school-developing skills and gathering essential knowledge in preparing yourself to become an active, intelligent citizen of our democracy. But-what about the vacation period next summer? You will have some three months available then. How can you use that time to make the maximum contribution to the war effort? The serious shortage of workers in our farm areas provides a challenging answer to this question.

\section{Agriculture-A National Industry}

Agriculture is the oldest occupation of civilized man. Tending flocks and producing crops for food and clothing-the necessities of life-were some of his earliest productive activities.

When we think and speak of agriculture, it is generally in terms of an individual farm. Consequently, we often think of it as a small industry or business. But in 1940 agriculture in the United States ranked second only to manufacturing in the number of workers employed. Eighteen and five-tenths percent of all employed persons were in agriculture. On the basis of net income, agriculture ranked fourth among the industries, being exceeded only by manufacturing, trade, and finance. It has been estimated that in 1937 each farm person produced enough food for himself and three and one-half additional persons. A major portion of our population is wholly dependent on commercial agriculture for food and clothing.

\section{Agriculture - An Essential War Industry}

In normal times agriculture is an essential industry of the Nation; in war times it assumes vital significance. Production goals in 1943 in 
the United States call for an increase of 10 percent over the 1941 levels. Secretary Wickard has said that about one-fourth of this production will be needed for the armed forces and for lend-lease shipments. Farmers of Illinois have been asked to increase their 1943 production over that of 1942 by the following percentages: corn, 4 percent; barley, 12 percent; potatoes, 8 percent; cattle, 3 percent; hogs, 15 percent; chickens, 8 percent-and these are only part of the items.

As a result of the increased efforts of farmers, favorable weather and the influx of older men and women and children to farms making a barely adequate labor supply, agricultural production was at a high level in 1942. Total production is estimated to have been 9 percent above 1941 , whereas production goals called for only a 6 percent increase. Corn, soybean, and pork production all set new records.

American farmers have successfully met the challenge of the first year of the war. But, with the demand for still further increases, what is the prospect for 1943 ?

\section{The Farm Labor Situation}

Farmers are being asked for further increases in the production of a number of commodities in 1943. Statistics show that about $1,600,000$ farm workers and operators left their farm jobs between September, 1941, and September, 1942, 43 percent to enter the armed forces, and 57 percent to go into the ranks of industry. A great many more have left since September, and the number that will be called to the armed forces in 1943 will continue to deplete the already inadequate supply.

In a recent survey, more than one-third of America's farmers said that unless they could obtain help from sources other than those now available, they would have to greatly reduce their output in 1943.

The need for additional food production in 1943 is vital. Without it the tremendous task of feeding large numbers of the civilian population in allied and conquered countries, as well as the members of our armed forces and the people of our nation, cannot be done. We cannot, we must not, disappoint these people. They depend on the products of agriculture for the garments that clothe them, and for the food which provicles the physical stamina needed to wage a successful fight against the enemy.

\section{A Challenge to the City Youth of America}

This is where you, the city youth of America, fit in. The nation looks to you to help solve this crucial problem. Here is your opportunity to make a really impressive contribution to the war program. If you are physically fit, alert, and willing to learn, this is the chance you have been waiting for to back up the men on Democracy's fighting fronts with actual deeds, while at the same time improving your own physical trim, laying up funds for the future, and gaining skills that will always be valuable. Don't let your country down. Help it solve its farm labor problem! 
1)

\section{Work, Wages, and Living Conditions}

\section{The Nature of Farm Work}

Before deciding to work on a farm, you should consider rather carefully whether you "can take it." Farm work is hard work. Naturally not all the jobs you will be asked to do are difficult, but there are a number of jobs, such as pitching hay, which require a great amount of physical exertion. Farmers cannot use boys who are physically soft or lazy. If you are not willing to do hard work, you had better forget about working on a farm. Farmers generally will recognize your limitations and not expect you to do work which is too strenuous for you, but they will expect you to do your very best on the physically hard work. If you are looking toward next summer on a farm as a time to relax and take life easy, forget about farm work! The farmers are too busy in this war effort to be bothered by persons who are not willing to work. On the other hand, if you are ready to accept a challenge to your physical vitality and ability, a number of farmers will be glad to have you work for them.

The physical exertion re-

Pitching hay is typical of work done in the fields during the summer months. It is hard work, and skill is required if a satisfactory amount of hay is to be put in the barn each day. Hay can be put up only when dry, and since it is of inferior quality if rained on, farmers are in a hurry during the haying season.

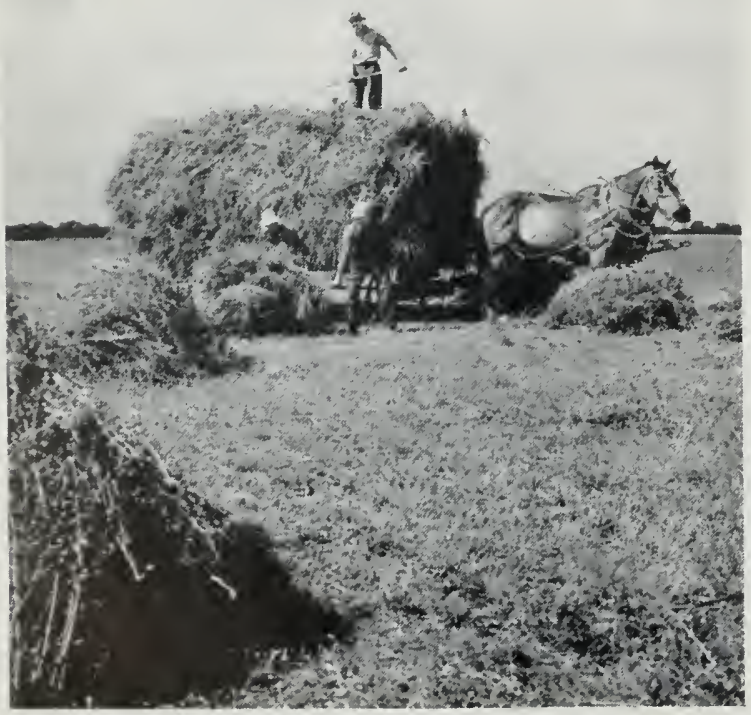
quired for farm work is not just a matter of being able to lift a bag of feed; it involves endurance. We hear much talk these days about keeping fit. If you work on a farm this summer, you will be doing a great deal towards maintaining "physical fitness." Fresh air, sunshine, plenty of food, lots of sleep, and an abundance of exercise will condition you physically.

Now, how about your working hours? It is important to remember that, unlike business men, the farmer doesn't keep "office hours." Much of his work can be done only when weather conditions are favorable, even though there are some farm jobs that must be carried on rain or shine. Since the weather period favor- 


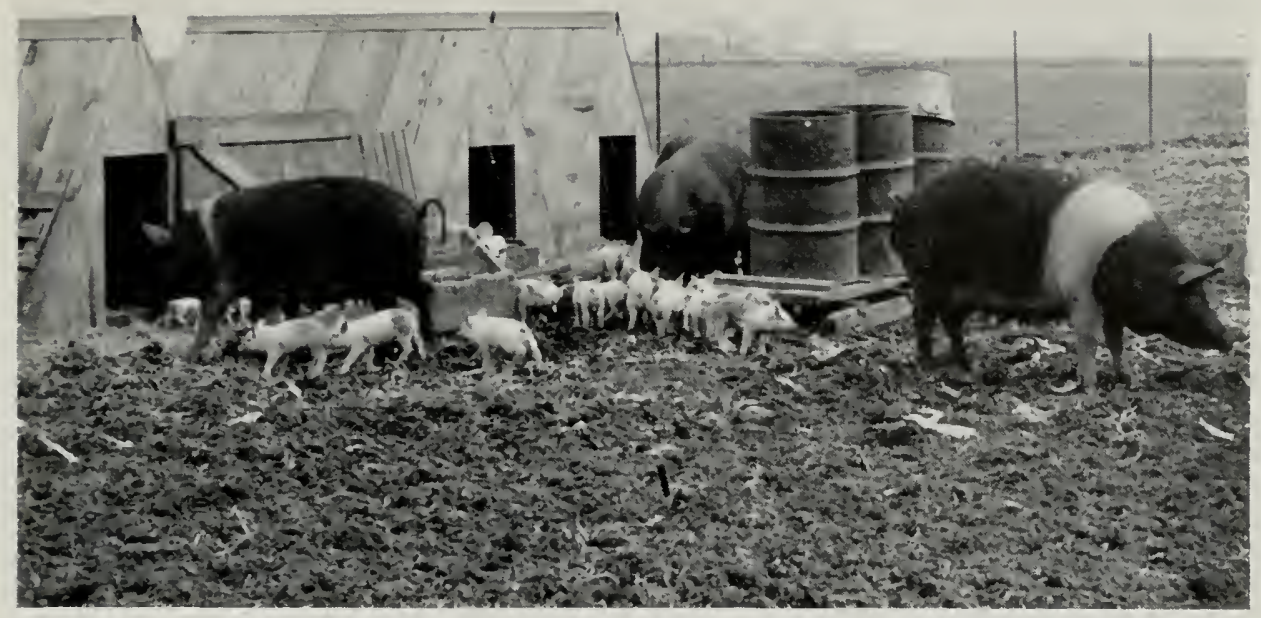

On livestock farms much time is devoted to "chores." Sows with little pigs will be fed and watered twice each day and the bedding changed when it gets damp. Later these pigs may be put on a self-feeder.

able for certain operations is often short, the farmer literally must "make hay while the sun shines."

There is no "eight-hour day" on a farm, either. There will be times on any farm when you may be expected to work ten or twelve hours a day, and on some farms such hours may be the rule rather than the exception. It is interesting to note, however, that despite longer hours, statistics show that rural people are generally as healthy as city dwellers.

Finally, you must keep in mind that the farmer does not have a "white collar" job. Just as he does not keep office hours, neither does he wear office clothes. You will be asked to perform jobs at which you cannot keep clean, some of which you may even consider unpleasant. If you are on a livestock farm, it is likely that you may be asked to help clean out the barn or feedlot; this means shoveling or pitching manure. During harvesting, if you work around a combine, baler, or threshing machine, you may find the job a dusty one. If you operate a tractor cultivator on a windy day, you may find that when you stop work the only visible white spots on you are the whites of your eyes. Naturally only a relatively small percent of the farm jobs are extremely dirty, but if you cannot stand dirt, don't accept farm work.

The type of jobs you will be asked to do on the farm depends on the type of farm on which you work. You may be expected to do a wide variety of jobs, or the farmer may want someone who will do the same work all the time he is on the farm. Information contained in this booklet will help you visualize the jobs to be done on different kinds of farms. They will range all the way from various tasks in the care of the dairy herd, horses, pigs, sheep, beef cattle, or poultry to operating farm equipment such as tractors, plows, binders, and threshing machines, or planting, cultivating and harvesting the crops. 
It takes more than just muscle to do the job. Farm work calls for stamina and physical endurance. Remember, too, that in the farmer's eyes you will be a comparatively "green" worker. It takes years to develop a truly skilled farm worker, and in the beginning you may be more of a liability than an asset to him. To be successful, you will have to follow his instructions carefully and accurately, and work hard at the tasks assigned you.

\section{Wages and Living Conditions}

One of the first questions in the mind of anyone considering a job is that of wages. It is rather difficult to say exactly what wages you can expect. In the summer of 1942 inexperienced city boys who accepted farm work for the entire summer received about a dollar a day plus room, board, and laundry. With the increased demand for workers in 1943 and rising farm prices, it may be that some farmers will be willing to pay more than this for boys who demonstrate their ability and willingness to do farm work.

In arriving at a total wage, you will have to add to your cash wage the value of food, room, laundry, and whatever else may be furnished. The value of these additional items may be more of a real advantage to your parents than to you because most of you still live at home where your room and board is furnished. Though wages may appear small, you will undoubtedly be able to save some money since your major needs will be supplied, and there will be many enjoyable ways to use your spare time that do not require spending any money.

Living conditions vary from farm to farm. Many farmers have completely modern homes; others have none of the modern conveniences. When you go to work on a farm, you may expect to be considered pretty much as "one of the family"; in fact, if the farmer has a son of about your age you may be asked to share his room. Generally speaking, most farm homes are clean and have comfortable sleeping rooms. You will receive plenty of substantial food, even though it may not be in the form of some of the fancy dishes and style you have been accustomed to in the city.

Over one-fifth of the total number of people in our country are farm workers or farm dwellers. Here is an opportunity for you to develop an understanding of these people, their life, and problems, and make many friendships which you will appreciate in years to come.

\section{There's a Place for the Girls, Too}

High school girls who are interested in helping out the farm situation will not be excluded from jobs this summer! The greatest demand for workers will no doubt be for boys since many of the jobs require hard physical labor. Although the heavier field work and machine operations will be performed by the men, you high school girls can help with a great many of the tasks discussed in the following pages. 
Your greatest value will probably lie in the work that you do around the farm home-helping with the general housework, cooking, and working in the garden. If a large share of the household responsibilities can be delegated to you, the more experienced farm women will be able to pitch in and help with some of the skilled operations around the farm, such as driving the tractor, etc.

\section{A Contribution to War Effort and Personal Development}

The preceding information has given you a general picture of what you may expect if you decide to accept farm work. In arriving at a decision, take into consideration what jobs are available in the city and the wages they pay.

Get different opinions by talking to several of the boys in your school who worked on farms last summer. Some of them will be enthusiastic about it; others may report unfavorably. Try to get enough reactions and comments to enable you to make an intelligent decision.

Keep in mind that working on a farm is a direct contribution to the war effort in two ways: First, it means helping to relieve the labor shortage that threatens to cut down our supply of essential food and clothing. Second, it develops a quality in you that is needed in our fighting menphysical fitness. You may be in the armed forces before this war is over.

Remember, too, that education through experience, the most effective of all teachers, is at your service. A relatively large share of this education is general enough to have value to you in everyday life. There is an opportunity to use many of the small tools and equipment on a farm in other lines of work, and to develop a variety of manual skills. There is much for you to gain personally at the same time that you contribute to the war effort.

For those of you who have a lively interest in plant or animal life, and have enjoyed your botany or biology classes, farm life offers unexcelled opportunity. Your experience in tending living, growing plants and animals will be invaluable in helping you to observe, note, and understand the principles you have studied.

Think over all these things. Then, having received your parents' consent, the final decision lies with you.

On many farms the poultry will be fed and watered by girls, so that the men will have more time for field work.

PAGE 11

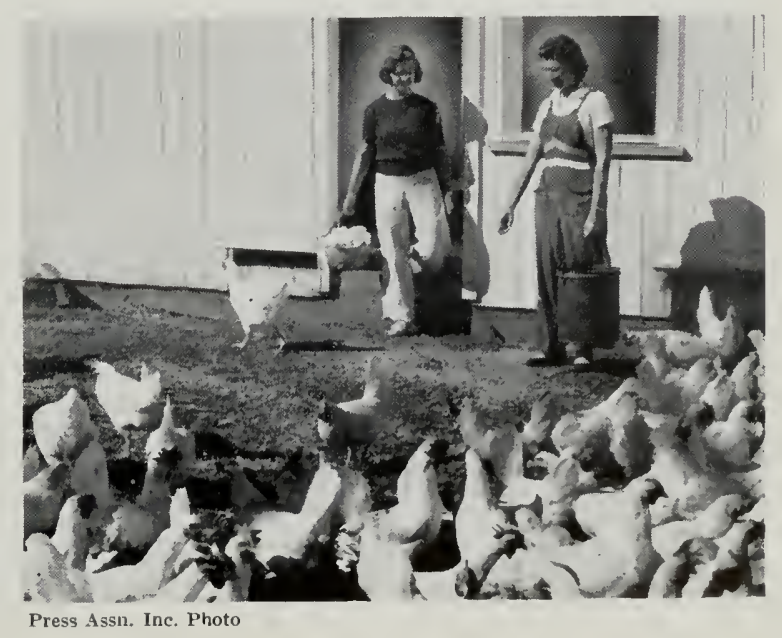


2)

\section{Preparing and Planning for Farm Work}

\section{Start Making Plans Now}

This program can't be expected to be one-hundred-percent perfect. It would be surprising if every boy who attends these meetings were to be placed on a farm next summer. It would be equally surprising if every one of you "stuck it out" after being placed on a farm! However, preparation and planning will help to work out a program that will be as nearly perfect as can be expected. The main purpose of those who are responsible for the program is to see that you will be happy in your work, and that the farmers, in turn, are satisfied with your help.

What preparation and plans should you be making now?

It has been pointed out that farm work is hard work physically. It will also require you to do a lot of thinking and to make a number of decisions. One of your first tasks is to prove to those who are offering this training that, physically and mentally, you deserve to be chosen for a farm job. To be a real aid to some farmer next summer, it will be necessary for you to start right now to prepare, both physically and mentally, for your job.

A flock of sheep requires a lot of attention at lambing time in late winter or early spring.

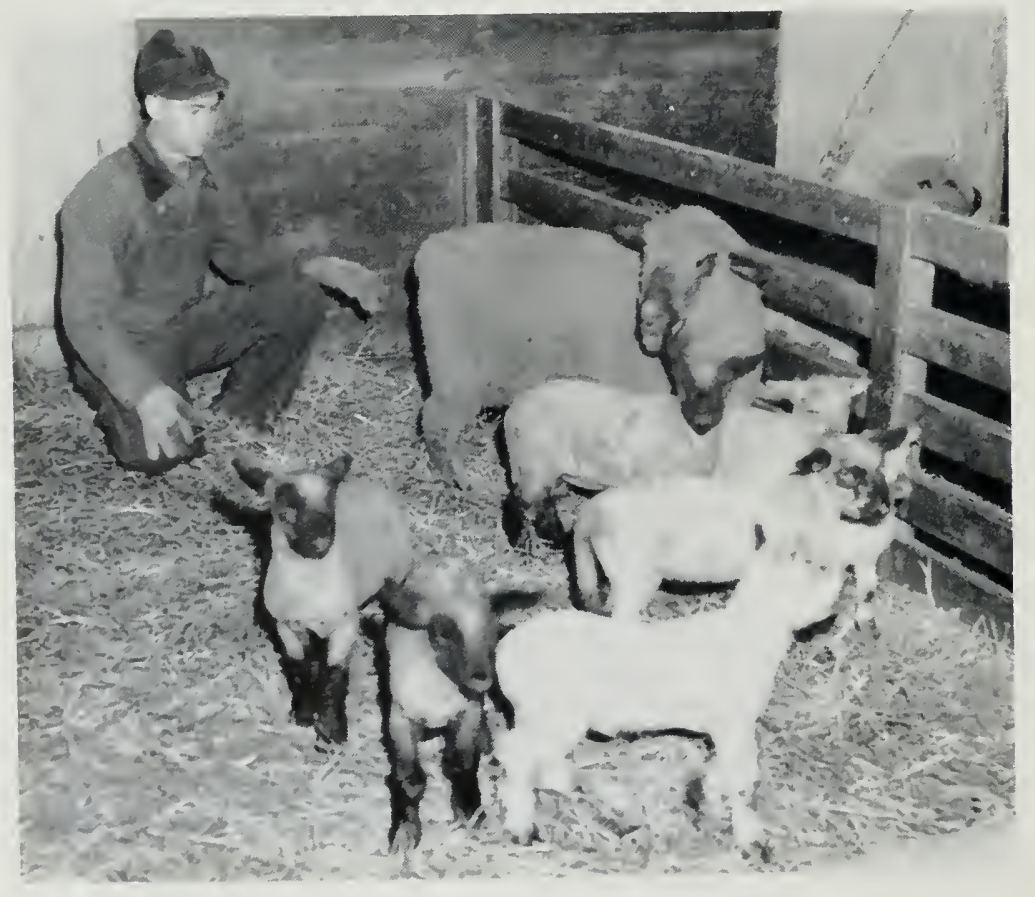

Well-made plans are important in any enterprise. Start making yours for this undertaking now; then put them in to effect at the first opportunity. Of course, we all realize that under present emergency conditions, even the best laid plans may go awry, but that possibility should not deter us from making plans and then rearranging them if it becomes necessary.

PAGE 12 


\section{Personal Preparation- Physical and Mental}

Take advantage of every opportunity to increase your knowledge and experience in regard to agriculture.

Meetings will be held at various centers in your city. These will be designed especially for city youth who are planning to work on farms this summer. Qualified men, experienced in various phases of agriculture, will talk to you and

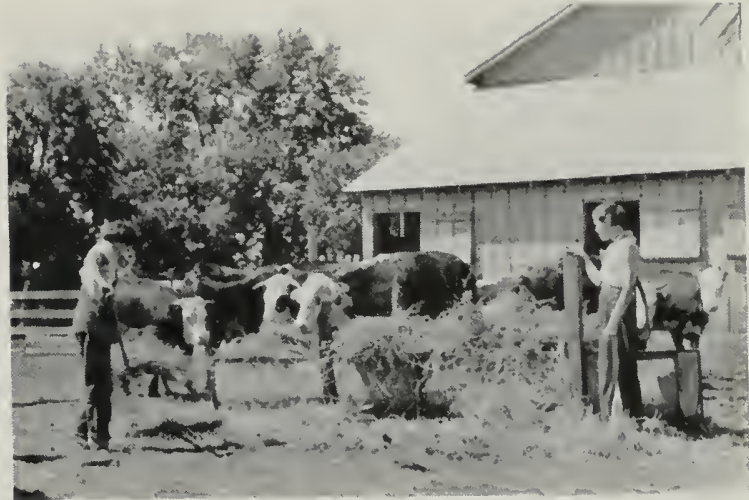

These farm girls are feeding hay to their father's Hereford cows (beef cows) in an outside rack. Most farmers will be unwilling to use city girls for caring for livestock, but city boys can be a lot of help at this "job. lead discussions at these assemblies.

Preceding each meeting, you will be given printed material to read. Study it carefully. Come prepared to ask questions and enter into the discussion. One or two ideas which you pick up, or questions you raise, may prove of inestimable value to you and the rest of the group.

Do not stop at this point. There are many good books on farming, farm life, and agriculture. Get acquainted with them for you can't learn too much. Although this so-called "book learning" will not be one hundred percent effective in preparing you for farm work, you will find many of the books extremely interesting as well as highly instructive.

Read the farm section of your newspapers and magazines. Farm magazines invariably contain instructive and interesting material. Take advantage of the mass of available publications on farming.

In personal preparation, a program for physical fitness must not be overlooked. Condition yourself physically by entering wholeheartedly into your school sports, for farm work requires toughened and hardened muscles. Get accustomed to being out in the open air and doing physical exercise for an entire day.

\section{Learn by Visiting}

Finally, remember that the shortest road to the most learning is right on the farm itself. If you can possibly arrange to do so, go out on a farm over week-ends or during any vacation you may have between now and next summer. That is also the best way to find out whether you really want to do farm work and are suited for it. Contact the personnel officer of your school and he will attempt to place you on a nearby farm for a week-end or so, by getting in touch with the United States Employment Service or the Farm Labor Committee in a nearby county.

Another way to learn to identify livestock, machinery, and crops is to make visits to places in cities where you will be able to see actual examples of them. Supplement your extra reading, and greatly add to your practical knowledge, by visiting stockyards, produce dealers, machinery manufacturers, or implement dealers.

If a large group of interested students can be gathered together, it may be possible to arrange for a regular guided inspection tour. This is one of 
the most valuable ways to learn about the animals, crops, and machinery you will be dealing with this summer.

\section{Placement Plans}

If you prove to those in charge of the training program that you are qualified for, and really interested in farm work, every effort will be made to place you with a farmer who has indicated a willingness and desire to use relatively inexperienced workers.

You will be asked to register for farm work and the farmer will also fill out a form. Then the farmer's request for a worker will be matched with the information on the student registration cards. In that way, it is hoped that boys will be placed on the type of farms they prefer and are best fitted for.

The labor training program is not a one-sided affair. The problem of using inexperienced help is being discussed with farmers at meetings this winter. The farmers are familiar with this entire program, and will recognize that you are not seasoned, experienced farm hands.

Another way to get placed on a farm this summer is to do so on your own initiative. If you have farm friends or relatives, get in touch with them. They may have something for you. If you do accept a job, be sure to notify the agency which has your registration card. Otherwise, valuable time may be wasted trying to place you.

Those in charge of this program believe that most of the capable and willing city boys who complete this training course and follow the plan outlined for placement will stand a good chance of being placed on farms next summer. They are convinced that the success or failure of your summer will depend on how conscientiously and industriously you prepare and plan for it.

The following is a list of books and papers which will help you to know more about living and working on a farm.

\section{Books}

Andersen, Homer Paul. "Your Career in Agriculture." E. P. Dutton \& Co., Inc. 1940. Campbell, Alfred S. "An Introduction to Country Life." Princeton University Press. 1936.

Deyoe, George P. and Ullrich, Fred T. "Getting Acquainted With Agriculture." The Interstate Printers \& Publishers. 1941.

Grim, James S. "Introduction to Agriculture." Allyn and Bacon. 1935.

Scott, Winfield and Paul, Joseph B. "Permanent Agriculture." John Wiley \& Sons, Inc. 1941.

\section{Pamphlets}

Hayne, Ralph A. "Stop Carelessness! Prevent Accidents!" International Harvester Company.

University of Illinois. "Shall We Move to the Country?" Circular 479. College of Agriculture. 1937.

U. S. Department of Agriculture. "Seedtime and Harvest Today." Miscellaneous Publication No. 485. U. S. Government Printing Office. 1942.

\section{Magazines}

Hoards Dairyman, W. D. Hoard \& Sons Co., Fort Atkinson, Wisconsin. Published the 10 th and 25 th of each month.

The Prairie Farmer, Prairie Farmer Publishing Co., Chicago, Illinois. Biweekly.

Successful Farming, Meredith Publishing Co., Des Moines, Iowa. Monthly.

Wallaces' Farmer and Iowa Homestead, Dante M. Pierce, Des Moines, Iowa. Biweekly. 


\section{Dairy Cattle-Responsibilities for Feeding and Milking Them}

\section{Cows Are Sensitive Animals}

Work on dairy farms is being discussed first because of its importance. Dairying is the most important farm enterprise in the vicinity of large cities and requires a larger labor supply than most other types of farming. Therefore, there is more than a fifty-fifty chance of your working on a farm where dairying is a major part of the farm business.

The modern dairy cow is a sensitive animal highly developed for producing milk. Even a strange person in the barn will cause many dairy

These are typical specimens of the five important dairy breeds. From left to right they are: Jersey, Guernsey, Brown Swiss, Ayrshire, and Holstein. Note differences in color, body shape, shape of head, and type of horns.

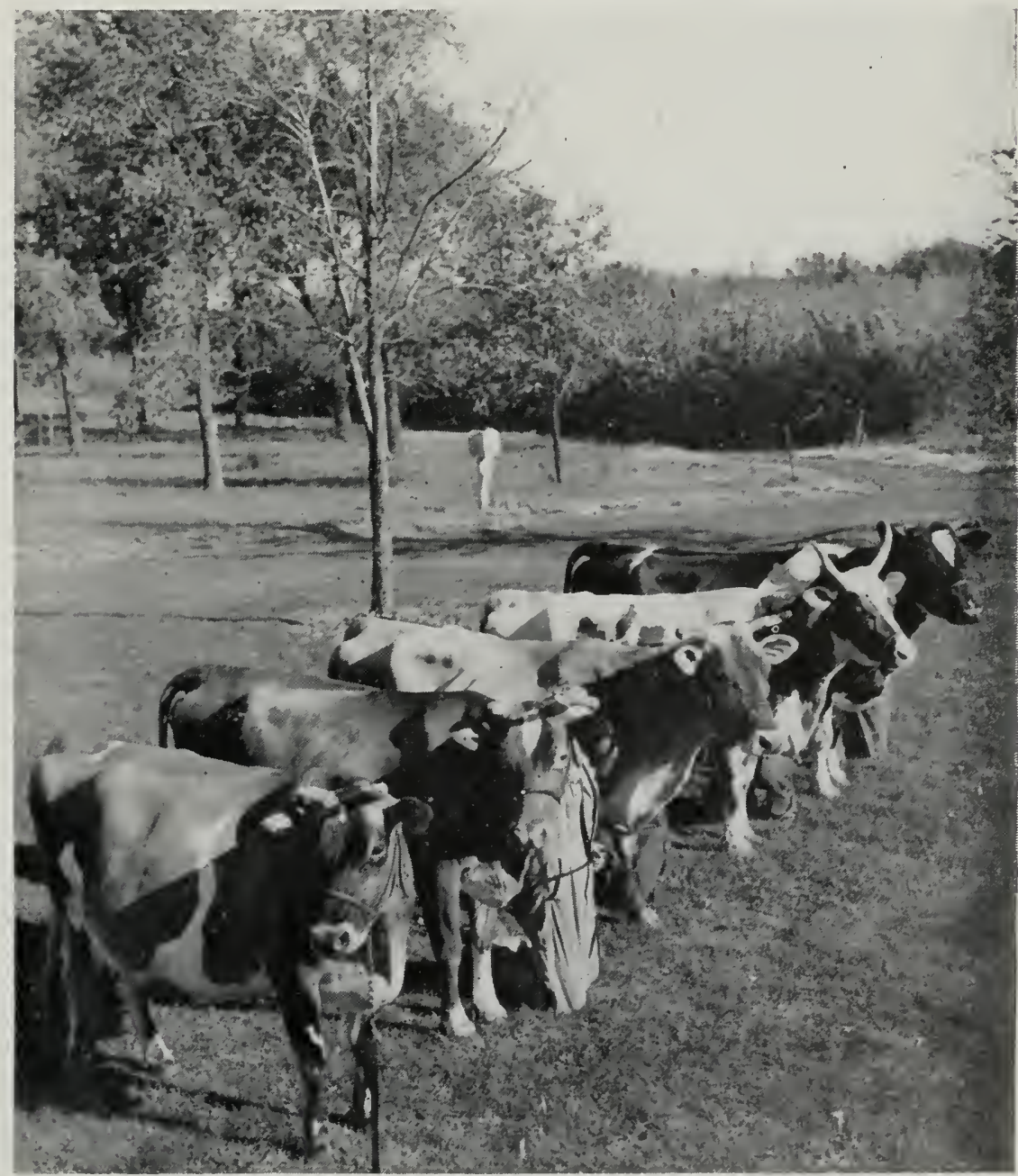




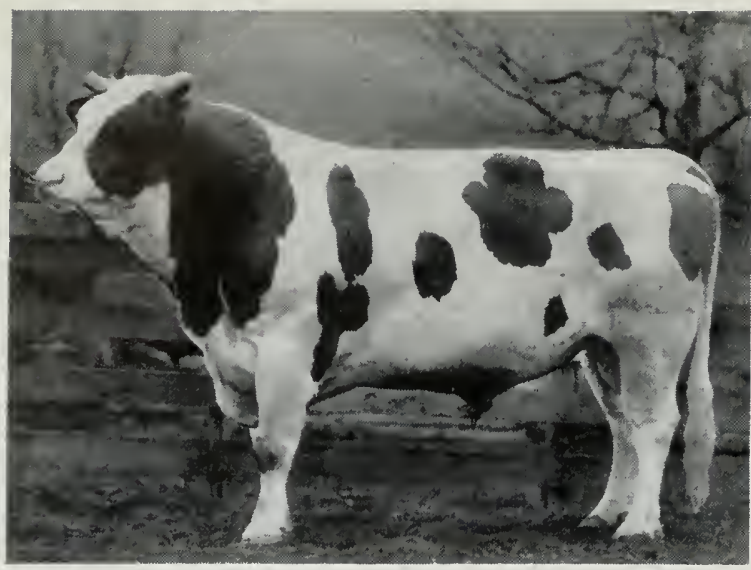

Bulls should be confined in well-built pens, and wise farm workers will stay out of these pens. The bull should be lead with a staff in the nose ring rather than with a rope.

cows to fall off in their milk production. A worker must therefore be skilled in caring for the dairy herd if he is to get maximum production from it. Care in feeding and management may easily mean the difference between getting 30 or getting 40 pounds of milk per cow daily. When you go on the dairy farm, study the cows. Here are animals producing some of the most important food products in the world. Ask the farmer which cows are the best producers and then see if you can determine what features make them so.

\section{Terms You Need to Know}

When you start work on a farm you will adapt yourself to the work much more readily if you are familiar with some of the terms the farmer will use. A number of these terms and their definitions are listed below to aid you in developing a vocabulary for discussing or commenting upon dairy cattle:

Cow-female of the species after she has produced her first calf.

Bull-male of the species.

Heifer-young female animal, usually so-called up to the birth of her calf when she starts producing milk.

Calf-young animal usually under one year of age. Its sex is indicated by referring to it either as a heifer calf or a bull calf.

Yearling - an animal, either male or female, between approximately one and two years of age.

Dry cow-a mature cow not producing milk. Dairy cows are ordinarily given a rest from milk production for three to six weeks after the end of a lactation period and before the next calving. During that period they are referred to as dry cows.

Milk cow or milker-a cow in milk production or producing milk.

To calve or to freshen-to give birth to a calf. Cows are normally bred to freshen once every eleven or twelve months.

Springer-a cow or heifer nearing calving time (due to calve or freshen in the near future).

Whole milk-the normal milk as it comes from the cow.

Cream separator-a machine for dividing whole milk into cream and skimmed milk.

Stripping-milking the cow dry by hand, after the milking machine has been removed. 
A breed-a race of animals having similar characteristics or features as a result of originating from the same parental stock. Most of the ancestors of purebred animals can be traced back many more generations than can most of our ancestors. The common breeds of dairy cattle in Illinois are the Holstein (black and white), Guernsey (fawn and white), Brown Swiss (brown), Jersey (fawn), and Ayrshire (red and white). The three breeds first mentioned are by far the most common in areas where whole milk is produced for the market.

\section{Care of a Dairy Herd}

For the purpose of discussion we shall divide the care of a dairy herd into five categories.

1. Handling the dairy herd. The prime requisites for success in the handling of any class of livestock are intelligence, kindness, patience, and gentleness. The dairy cow responds to kind treatment by increasing her production.

Generally speaking, dairy animals, with the exception of the bull, are not dangerous. Occasionally a cow with a small calf may be dangerous to strangers due to her natural instinct to protect her young. If you are kind and gentle to animals, however, you will soon gain their confidence.

On many farms the cows are milked with machines and most of them are "stripped" by hand. Clean milk is produced with clean utensils, from clean cows, in clean barns.

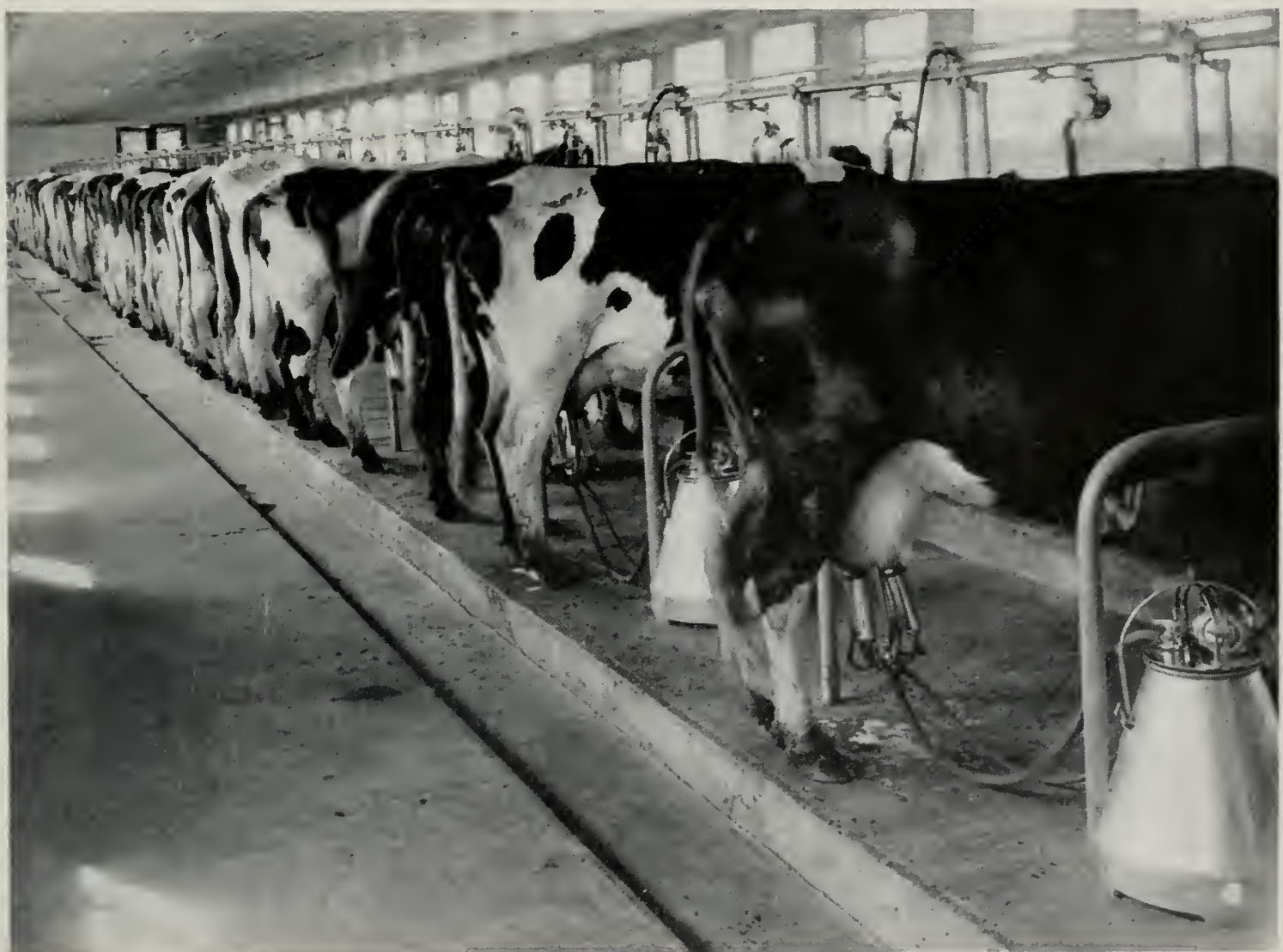




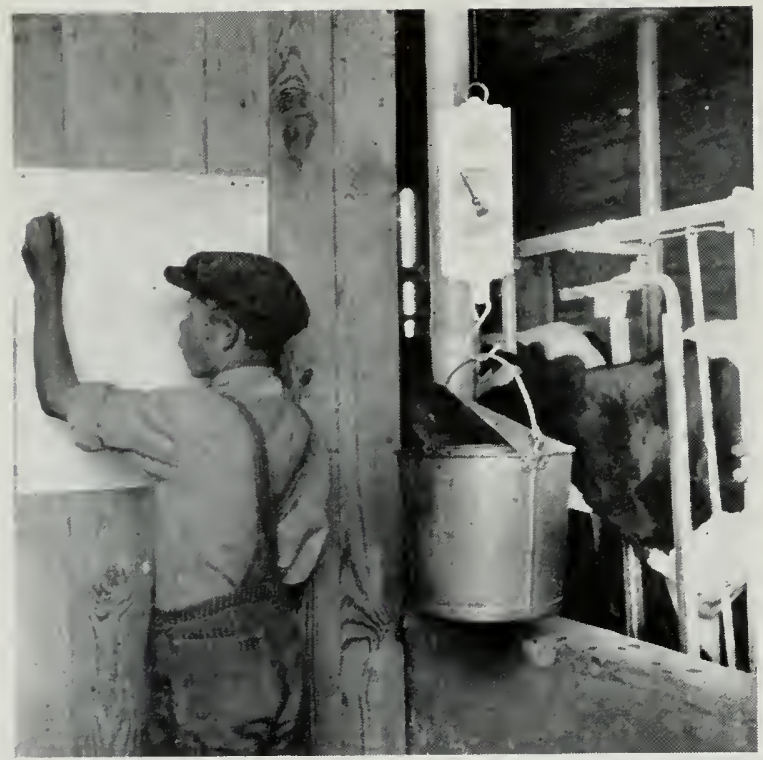

One of your jobs may be to weigh the milk from each cow at each milking and record the weight on the wall chart. However, not all farmers keep an accurate record of the production of each cow.

Your duties in dealing with the herd may consist of driving up the cows from the pasture if they are not at the barn, letting them in the barn for milking, and turning them out to pasture after they have been milked.

Now these are relatively simple jobs; after the dairy herd is acquainted with you, they will be easy to do. Here are a few things to keep in mind when handling the herd:

a. Animals are largely creatures of habit. They are accustomed to going in the same barn door and standing in the same stall. Do not attempt to change these habits unless it is absolutely necessary.

b. Cows normally are leisurely. If you use a horse to drive them, allow them to walk. Never send a dog after milk cows unless he has been trained to drive them slowly. Rough treatment reduces milk production.

c. Animals are curious. They are apt to go through any open gate either out of curiosity or in search of feed. You will save yourself time and trouble by always closing gates and doors behind you.

d. Animals expect direction. When driving animals in strange places don't expect them to know where you want them to go. You must indicate by your actions and your voice what you expect them to do.

e. It is wise to be cautious of the bull. Never handle the bull. Every year a number of farmers are seriously injured or killed by so-called "gentle" bulls. Never go into the bull pen when the bull is there. Some farmers may ridicule you; nevertheless, you should remember that the bull is probably the most dangerous animal on the farm and that very often it is the "gentle" bull that does the most damage.

f. All animals respond to kind treatment; still you must be firm enough to remain their master.

g. Contented cows are the best producers. The contented dairy herd shows its appreciation by higher milk production.

2. Feeding the dairy herd. Feeding practices vary from farm to farm. Therefore, be sure that you understand the farmer's instruc- 
tions and carry them out very carefully. As you gain experience, and especially if you study livestock bulletins and magazines, you will learn satisfactory feeding practices. Remember first of all, however, that you are working for the farmer and you must follow his instructions. If you think some change should be made, ask the farmer about it.

These are a few things to keep in mind about feeding dairy cattle:

a. Cows are fed roughages-hay, pasture, and silage-and concentrates-grains and mill feeds. The digestive system of the cow enables her to make good use of rough feeds.

b. Cows should be fed regularly. They cannot be fed as a coal stoker-enough at one feeding to last them several days.

c. Cows should be fed according to their production. If one cow produces twice as much milk as another, she deserves extra feed.

d. A constant supply of clean, fresh water is a necessity. Many cows produce 50 pounds of milk a day-that requires approximately six gallons of water just for milk production.

e. Salt should be available to cows at all times; it is an essential part of their diet.

3. Milking. If you are on a dairy farm, it is very likely that you will be expected to help with the milking. You may expect either to learn to milk by hand or to take care of the milking machine. The only way you can learn to milk is by practice, and that may be a rather long and trying procedure-for the cows as well as you. Keep in mind that milking involves more than simply draw-

Holstein cows on pasture. This farmstead, with its large dairy barn and twin silos, has room for a large dairy herd. You may be asked to drive the cows to the barn each evening and morning.

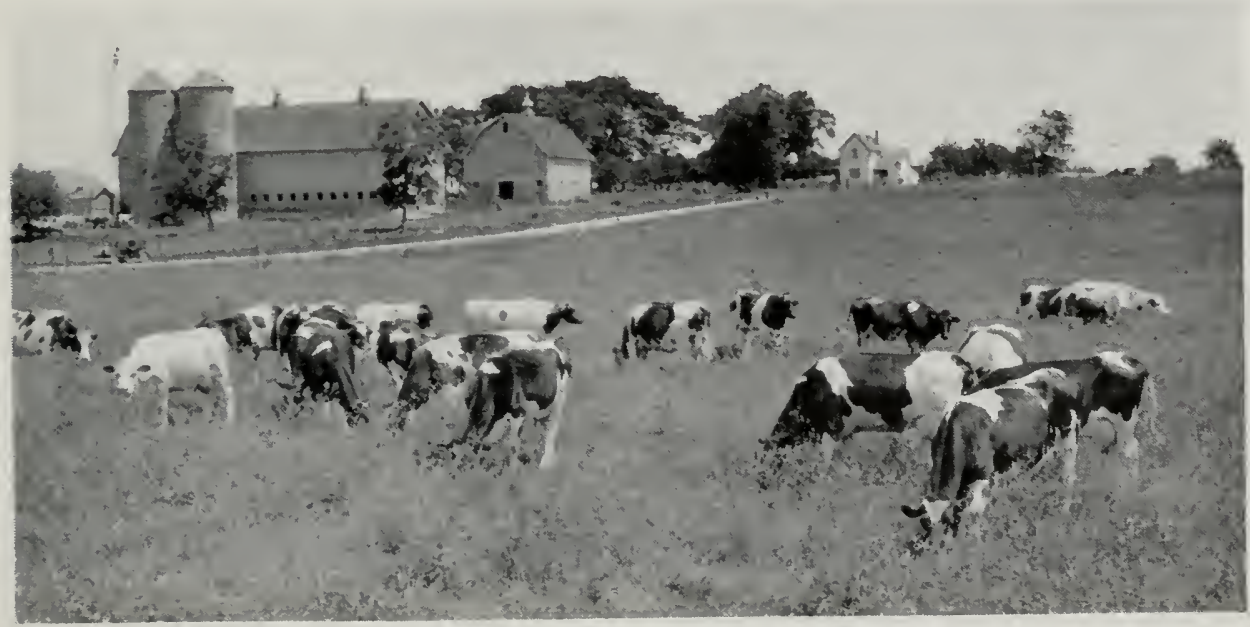


ing milk from a cow. The final product must be clean and safe for human consumption. Here again, practice, patience, and the ability to take and follow instructions are highly important.

4. Caring for the milk. Milk is a very perishable product. Since it sours rapidly under certain conditions, it must be strained and cooled immediately after milking. All parts and equipment that come in contact with the milk must be washed in hot water after each use. Milk produced on the farm tonight will not be in the consumer's icebox for at least 36 hours. If it is to arrive in a pure and wholesome condition, it must be kept clean and cool. Have you ever thought of how much effort is involved in producing the milk you drink each day? A summer on the farm will give you a greater appreciation of the farmer's job. Clean cows, workers, barns, and equipment are essential in producing a clean product.

5. Cleaning the barn. To produce a clean product, it is essential to clean out the milking quarters regularly. Manure and litter must be removed from the barn and, in most instances, loaded on the manure spreader and hauled to the field. This is some of the heavier and dirtier work you may have to do in connection with dairying. Farms producing for a whole milk market usually have to pass rather rigid inspections. The condition of the barn receives a lot of attention from the inspector.

\section{High Production Is Your Challenge}

Let us consider the problems of the dairy farmer. Dairying is his means of obtaining a livelihood. The sale of dairy products-whole milk or butterfat-is his major source of income. His main efforts are bent toward increasing the income from his herd. Even the crops he produces are used as raw material for the dairy cow in producing milk. The cow is often looked on as a machine which converts feeds, otherwise inedible for human beings, to highly nutritious foodstuffs for them.

The average dairy farmer has a rather large investment in barns, equipment, and cows. At the present time a dairy cow costs over one hundred and fifty dollars, and it is very easy to reduce the value of a cow as a milk producer through poor care and management.

Your challenge, in connection with the dairy herd, should be to try to obtain the highest possible production per cow under the supervision of the farmer. 


\section{Livestock-Care and Handling of Horses, Swine, Sheep, Poultry, and Beef Cattle}

\section{Think of Animals as Friends}

Your responsibilities in connection with dairy cattle were discussed at length in the preceding unit. However, almost every farm has not just one kind of livestock but several. Consequently you will have to be prepared to become, to some extent, a jack-of-all-trades. Regardless of the class of livestock, the successful herdsman must possess the qualities of gentleness, kindness, firmness, and, above all, patience. The characteristics essential for success in handling livestock, it is interesting to note, are the same as those possessed by persons who make the most friends and get along best in their associations with other people.

It will be possible to touch only briefly on each class of livestock. Most of your education in handling livestock will have to be acquired out on the farm. It is only possible here to depict for you what you may be expected to do and to offer some suggestions which will help you orient yourself on the farm more rapidly.

\section{Caring For and Handling Horses}

Illinois agriculture has become highly mechanized. In fact, in parts of the state there are farm boys who have never handled horses. However, the majority of farmers still have at least one team of horses which they use for certain types of work.

These are some things you may be asked to do with horses:

1. Feed and groom them.

2. Harness them.

3. Hitch them together and to equipment.

4. Drive them and operate simple horse-drawn equipment.

5. Unhitch and unharness them.

Horses generally are kept on the farm as a source of power. Occasionally a farmer keeps a riding horse for use in caring for other livestock or for pleasure, but most of your experience will be with draft horses, which furnish the power for doing numerous jobs about the farm.

While horses are considered quite intelligent animals, it is well to remember that their value depends to a high degree on their past training and response to certain signals. Usually these signals are vocal or given by exerting pressure on the reins or lines. For the most part, the horse depends on the driver to show him what he should do. If horses are handled by the same man for a period of time they become accustomed to that driver and may not respond readily to a new driver. Remember 


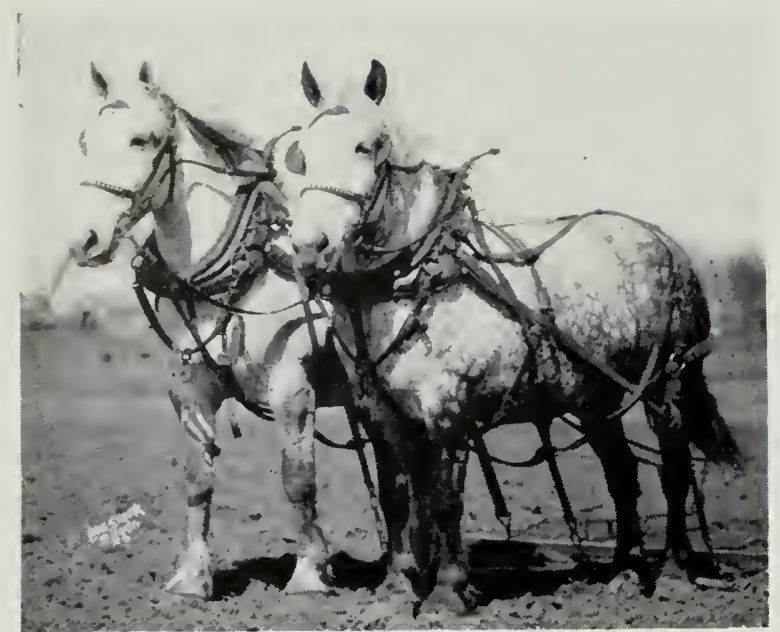

How would you like to groom, feed, water, harness, and drive this powerful team of Percherons?

that when you first take over the team you are as new to the horses as they are to you, and your inexperience really works a double hardship on the horses.

It is a pleasure to handle welltrained, gentle horses and you should not attempt to handle any other kind until you have had considerable experience. It is very seldom that one finds a vicious or mean horse. Although there may be some that have a bad habit of biting or kicking, they are exceptions. This is one rule that you must always observe in working with horses or with any class of livestock: Always warn a horse or other animal when you approach him. Speak to him as you draw near and before you touch him. If you do not, his natural reaction may be to kick in surprise when you touch him. If we were as inconsiderate in our treatment of other people as we often are in the treatment of animals, the world would be a very unpleasant place in which to live.

Horses must be fed and watered regularly, yet they must not be overfed, or watered when they are hot from heavy work. If you feed the horse be sure to follow exactly the instructions given by the farmer. Grooming is a cleaning procedure for horses and is a task likely to be assigned to you. A horse can neither give himself a bath nor curry (brush) his hair; yet, he is often in places which cause him to get very dirty. He appreciates being groomed, for like other farm animals, he is definitely handicapped when it comes to grooming himself.

You cannot learn to handle horses by reading about them. Here, too, experience is by far the best teacher. Remember there are numerous times when the horse might like to explain something to you, but unfortunately he can't talk. He is at your mercy, so treat him patiently and with kindness and understanding.

Here are a few terms which you should learn in connection with horses:

Gelding-a castrated or desexed male horse kept for draft or for riding purposes.

Mare-a female horse.

Foal-a nursing colt.

Colt-the young of the mare.

\section{Feeding and Care of Swine}

"Swine" is a term which includes all kinds and classes of pigs and hogs. We often hear the expression "dirty as a pig," but do you know that the pig is naturally one of the cleanest of the farm animals? He is the only farm animal who will not wilfully foul his own quarters; even little 
pigs only a few days old make their toilet away from their sleeping quarters. Pigs are often referred to as "mortgage lifters" because over a long period of time they have been one of the most profitable classes of livestock for farmers who care for them properly. Now the government has asked farmers to materially increase pork production. Along with dairy products and poultry, pork is one of the war commodities. You should be familiar with the following terms in dealing with swine:

Farrow (verb) - to give birth to young.

Gilt-a female pig before farrowing her first litter.

Sow-a female hog after farrowing a litter, usually over one year old.

Boar-a male hog.

Barrow-a castrated or desexed male pig fattened for market purposes.

Pig-young of the swine. Many farmer's use the term pig to include all swine up to their marketing age.

Hog-the difference between a hog and pig is mainly one of size or age.

Litter-the young of a sow produced at one farrowing, usually from 5 to 12 in number.

Castration-the operation for removing the testicles or reproductive organs of the male. Desexed male animals fatten more rapidly and produce higher-quality meat than do males.

Shote (also shoat) - a pig that is being raised or fattened for market, usually weighing less than 150 pounds.

Your responsibilities in connection with hog production may include one or all of the following:

1. Feeding and watering the fattening pigs

2. Helping to vaccinate and castrate pigs

3. Feeding and caring for sows and litters

Feeding fattening pigs is one of the simplest feeding tasks on the farm. There is danger of overfeeding most classes of livestock but not the pig. The farmer wants the pig to gain weight rapidly, so the pig's chief function is to "make a hog of himself."

The pig's digestive system is not adapted to the digestion of a lot of rough feed. Consequently his ration is made up chiefly of farm grains and mill feeds.

Feeding practices for hogs vary widely but generally one of two methods is used. Either they are fed twice daily, morning and

With a self-feeder of this type pigs get all they want to eat, and enough feed can be put in at one time to last several days.

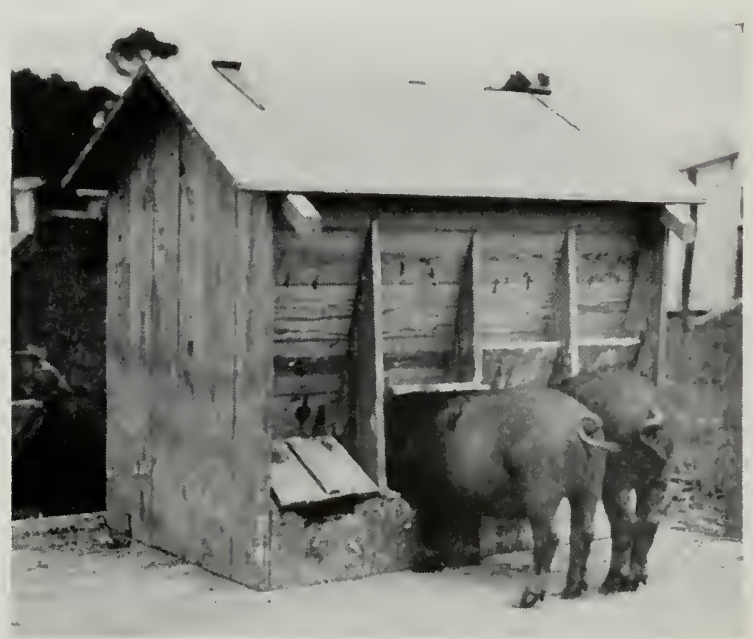




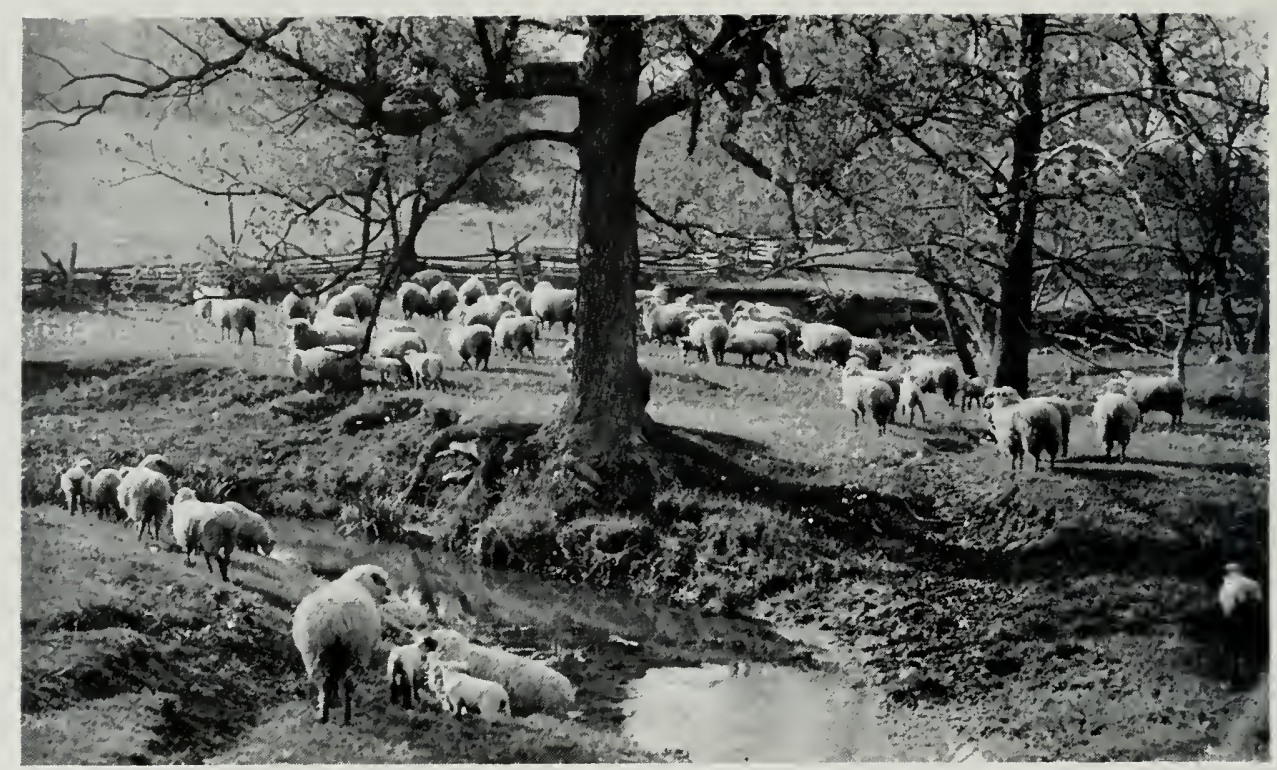

These ewes and lambs are getting both feed and water from the pasture, and so do not need much attention during the summer months.

evening, or they are self-fed. The latter means that a large quantity of feed is made available to the hogs at all times-a help-yourself or cafeteria plan. You will have to follow the instructions of the farmer you work for and use his system of feeding; he usually has reasons for his particular method. Be sure the hogs have plenty of water. They cannot stand heat. If fat hogs are excited or hurried in hot weather, some of them may die.

You may be asked to catch or hold pigs while they are being castrated or vaccinated. These operations may be performed by the farmer or he may hile a veterinarian to do them. In either case you may be called upon to help.

Pigs are usually farrowed, or born in the fall or spring. However, it is not unusual for farmers to raise summer litters. You may be asked to help take care of sows and their pigs. If so, follow the farmer's feeding instructions carefully. Take care not to disturb the sow unduly. Many sows are cross when they have small pigs, and almost any sow may be dangerous if anything is done to cause one of the pigs to squeal. Another precaution to practice when working around livestock is to leave the farm dog behind or he may endanger your own position. Dogs are natural enemies to most farm animals, and their presence will excite any animal which has young. Boars (male hogs) are sometimes mean or vicious; be cautious when dealing with them.

Of all farm animals, the pig will try your patience more than any other, especially if you try to drive him into a new place. The easiest way to get a pig to go where you want him to is to let him make his own decision to go there. A pig does not like to be forced anywhere. He may 
stand with his head in a door for several minutes before going in, but if you try to push him through he will invariably back out. It is this characteristic that undoubtedly has given rise to the expression "pig-headed."

\section{Feeding and Caring for Sheep}

Vocabulary :

Ewe-a female sheep.

Ram-a male sheep, often referred to as the "buck."

Lamb-a young sheep under one year old.

Wether-a desexed or castrated male sheep.

Feeders-sheep or lambs purchased to be fed and fattened for market.

The sheep enterprise is of relatively minor importance on most Illinois farms. A great many farmers keep no sheep at all. Feeder sheep or lambs are usually fed during the fall and winter months, so probably your work with sheep will be only with the breeding flock and the lambs produced on the farm.

During the summer months sheep require very little attention. The breeding flock needs nothing but pasture, plenty of clean, fresh water, and

Growing chicks need feed, water, shade, and shelter. These self-feeders have a roof which keeps the feed dry, and the brooder house is equipped with a stove for cool weather.

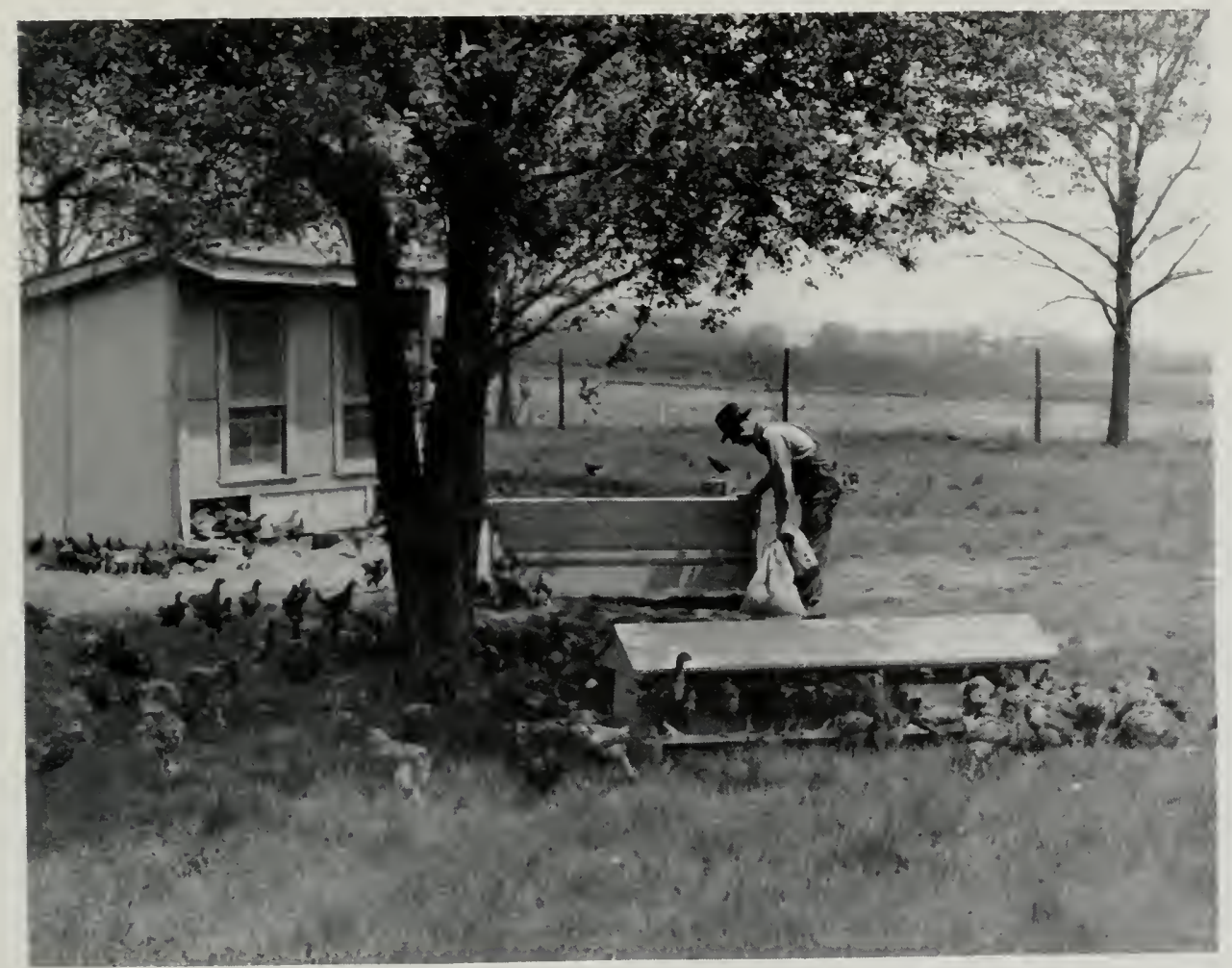

PAGE 25 


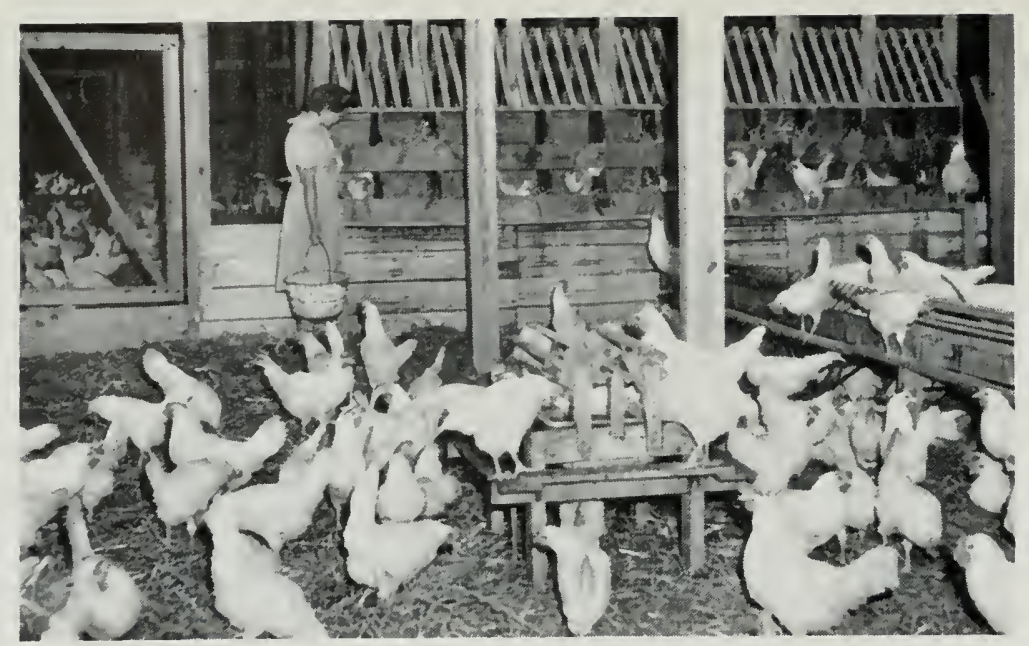

This is a well-equipped hen house, as indicated by the clean, dry litter, self-feeders, and ample nest space. Eggs should be gathered several times each day in hot weather.

salt. On some farms the lambs are fed grain to fatten them for marketing which, in Illinois, is usually between June and October.

In working with sheep you should remember that they are timid and are the most gregarious of all farm animals, that is, they go in flocks or stay together. It is very unusual to find one or two sheep very far from the rest of the flock.

Vocabulary :

\section{Caring for the Poultry}

Pullet-a female chicken under a year old.

Hen-a female chicken over a year old.

Cockerel-a male chicken under a year old.

Rooster-a male chicken over a year old.

Baby chicks-chickens a few days old purchased by the farmer to be raised for market or kept as laying hens.

Broiler-a chicken usually from 8 to 12 weeks old, produced for market and weighing 2 to 4 pounds.

Practically every farmer keeps some poultry. The size of his enterprise will vary from less than one hundred hens up to several hundred, and the number of chickens raised may vary even more. Caring for the poultry is usually considered as lighter farm work and very often the farmer's wife or younger children are given this responsibility. City girls may easily learn to care for poultry. Responsibilities in caring for the poultry may include the following:

1. Feeding and watering the laying flock.

2. Feeding and watering the baby chicks.

3. Gathering eggs.

4. Cleaning the poultry house. 
The digestive system of the chicken, like that of the hog, is limited in the amount of roughage it can utilize. Chickens cannot eat much rough feed and therefore spend a rather large portion of their time at the feeder. The most common method of feeding poultry is to keep feed in front of them constantly. If you are given the task of caring for the poultry, your most important responsibility will be to see that the flock has feed and water before it at all times. This applies to both old and young chickens. The other daily chore connected with poultry is that of gathering the eggs. This is done at least once a day, and in hot weather it is advisable to gather them several times each day because they deteriorate so rapidly at high temperatures.

The poultry house or houses will be cleaned regularly or irregularly depending on how the farmer cares for his flock. Some farmers clean the houses as often as once a week; others may clean them only once or twice during the summer. Cleaning involves removal of the straw, or litter, and droppings, and replacing them with clean litter. (In this case, "litter" is used in the sense of bedding for animals.)

As in the case of heavy-producing dairy cattle, the high-producing laying hen is a sensitive, highly developed, nervous individual. When working with poultry you should work quietly so as to avoid unduly frightening or disturbing the flock.

Beef cattle on full feed require large quantities of feed and water. These steers are fed grain twice each day, the grain being scooped from the wagon into the troughs. The hay is fed in mangers inside the barn where the hay is stored.

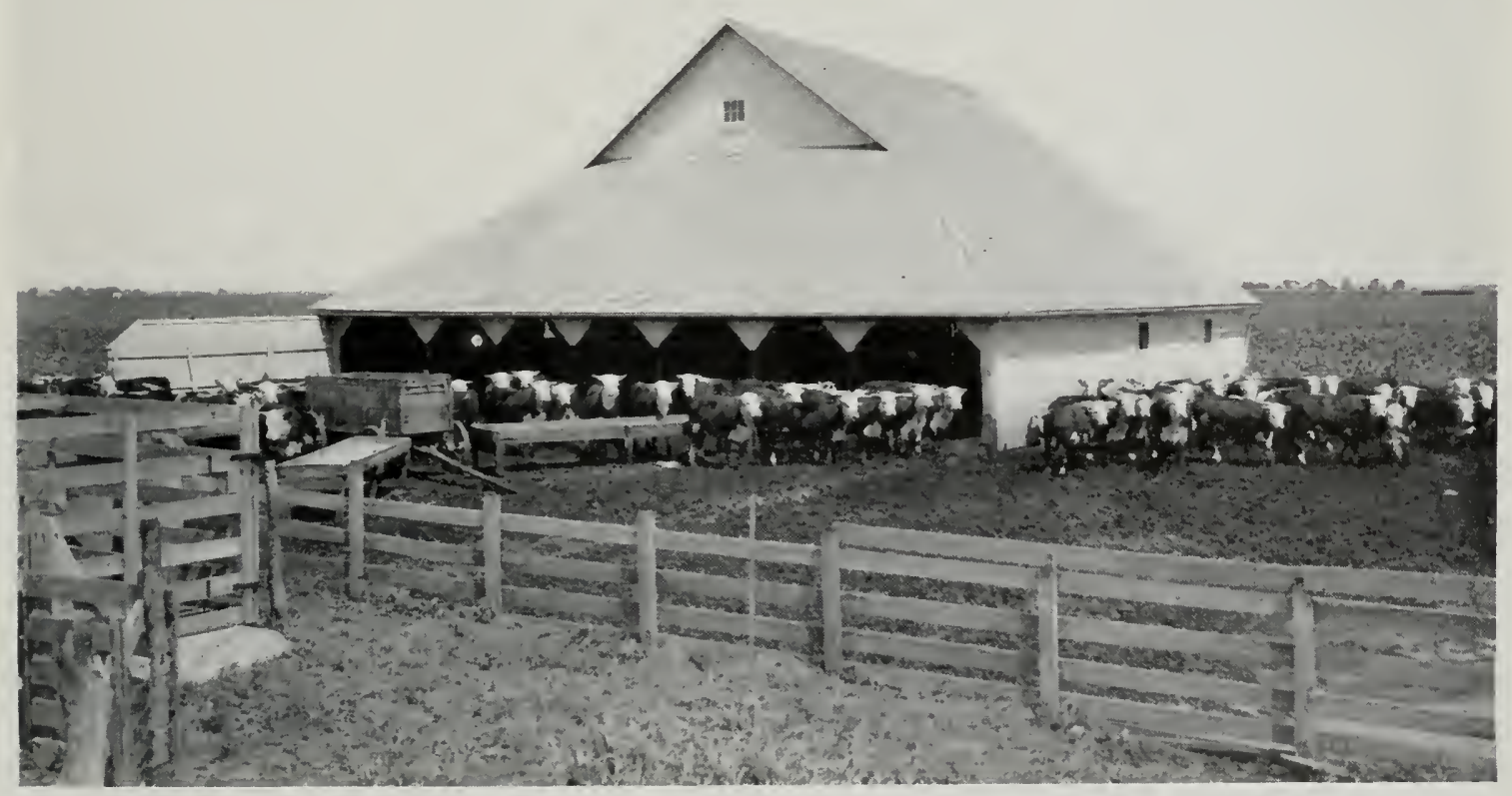




\section{Caring for Beef Cattle}

For a vocabulary of beef-cattle terms, review the one for dairy cattle. By adding the following two terms, your beginning vocabulary will be reasonably complete:

Steer-a desexed or castrated male animal to be fed and marketed as beef.

Feeders-beef animals (male or female) which are fattened for the market.

As in the case of sheep, the beef cattle may be divided into two categories-the breeding herd and the feeders. The breeding herd requires little attention during the summer months. Ordinarily the cows receive only the feed from the pasture on which they run. The calves may be fed some grain to help fatten them while they still are being nursed by the cows.

Feeder cattle may be handled in a variety of ways. They may be fed in drylot or on pasture. They may be fed heavily on grain, or heavily on rough feeds and light on grain. Feeders may vary in age from calves to two year olds, and they may be marketed at almost any time of year.

\section{Summary}

When you stop and think that books have been written about each of the classes of livestock mentioned, you can realize how limited is the scope of the material presented here. Very little has been said about the various breeds, but you will doubtless learn to know some of them after being on the farm for a while. The methods of handling livestock vary tremendously from farm to farm so we can give you no hard and fast rules to follow. Remember: you are going to be working for and with the farmer. To be successful, you must be able to take and follow his instructions.

There are a number of things which all farm workers should realize. First of all, the farmer produces livestock because he expects to realize a profit from them. Just as you expect to receive a wage from the farmer for your work, the farmer expects to receive his wage in the form of profits from his livestock. The skill with which you do your work will determine how much you are worth to the farmer.

The different classes of livestock are raised for specific purposes, the dairy cow to produce milk, beef cattle and hogs to produce meat, sheep to produce wool and meat, poultry to produce eggs and meat, and horses to furnish power. In feeding, caring for, and managing the livestock, it is up to you to do all the things that will enable them to perform their particular functions most efficiently.

Finally, you must recognize the limitations of animals. They cannot talk, they cannot reason, and their actions are largely the result of training and habit. Be patient, be careful, be kind, and be gentle, and you will probably enjoy working with livestock. If you enjoy your work, you will be more successful at it. 
5)

\section{Crop Production-Your Responsibilities}

\section{Crop Production Is Basic to All Agriculture}

Many farmers sell no grains but market only livestock or livestock products, which they have produced by using their grain as feed.

Clothing is made of fiber that is obtained either directly from plants, or indirectly from them through livestock, as in the case of wool. A number of crops, including fruits and vegetables, are consumed by man without being processed, while most of the grain crops (bread, cornmeal, and cereals are important exceptions) are first converted into meat or livestock products before being consumed by people.

Thus, it is evident that total agricultural production is dependent on crop production.

\section{Crops Raised on the Farm}

When you go to work on a farm, your employer is very likely to assume that you know the common crops raised on farms and that you can identify them. Some knowledge of the appearance and uses of the major farm crops will be an advantage to you.

Corn. Corn is the most important crop in Illinois agriculture. It is grown on practically every farm in the state and is the major feed for livestock. Over 85 percent of the total corn crop is fed to livestock. A small percentage of the crop is made into breakfast cereals, corn starch, corn syrup, and other products. Not only is corn high in nutritive value,

Can You Identify. These Grains When You See Them Growing in the Field?

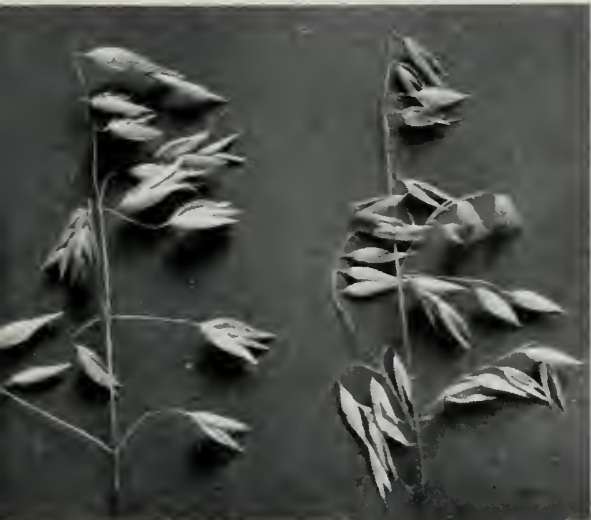

Heads of oats

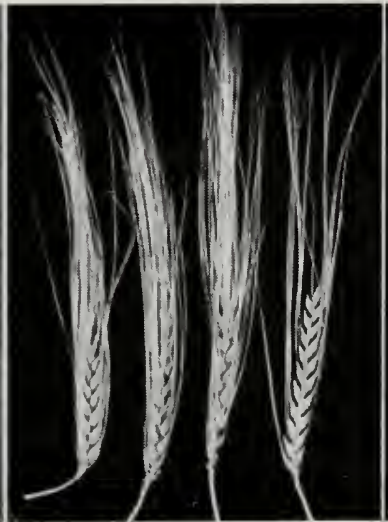

Heads of barley

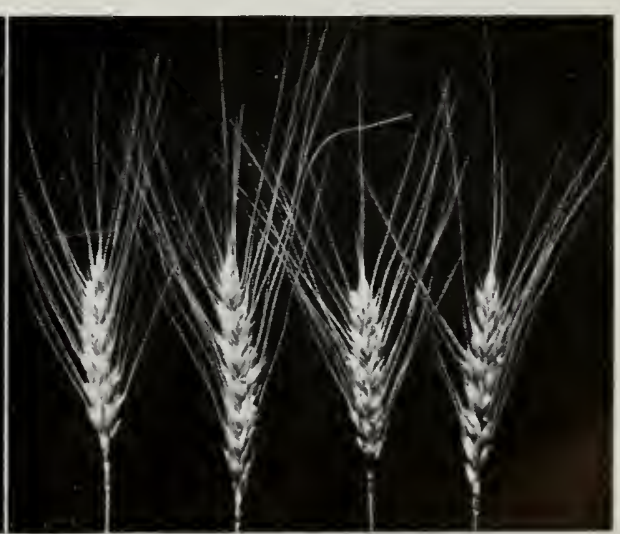

Heads of wheat 
but it also produces a larger amount of feed per acre than any other crop. On many farms it is raised as a cash crop; that is, it is sold rather than fed on the farm where it is produced.

You should get in the habit of differentiating between the terms food and feed. Products fed to livestock are designated as feeds or feedstuffs. Products consumed by people are referred to as foods or foodstuffs.

Oats. Oats are a small-grain crop used almost exclusively for feed. As a grain crop oats have been declining in importance in Illinois, although some oats are raised on most farms. They are more important in the northern than in the southern and central parts of the state.

Barley. Barley is a small-grain crop grown for feed and also as a cash crop to be sold on the market. Barley, like oats, does best in a cool climate and is grown chiefly in the northern third of the state.

Wheat. Wheat is a small-grain crop grown, to some extent, in all parts of the state and is a major crop in the southwestern section. The primary use of wheat in normal times, unlike the other grains, is as food for human beings. It is therefore grown almost exclusively as a cash crop. At the present time there is a surplus of wheat in the United States; consequently the price is low and farmers are using some of it as feed for livestock.

Soybeans. The soybean is the newest of the important farm crops in Illinois. It is an extremely important crop in the east central cash grain area. The chief value of the soybean is in the oil contained in the seed, which is used as a food, for making soap, and in paints. The meal which remains when the oil is removed is used primarily for feeding livestock, while a small proportion is used for making plastics. Since the beginning of the war the United States has been unable to import normal quantities of oils; consequently the soybean has been classed as a war crop. Some soybeans are produced in all sections of the state, and a minor portion of the crop is harvested for hay. The 1942 production of soybeans was almost twice as large as in any previous year.

Soybeans may be planted solid with a grain drill and not cultivated, or they may be planted in rows and cultivated with a corn or bean cultivator.

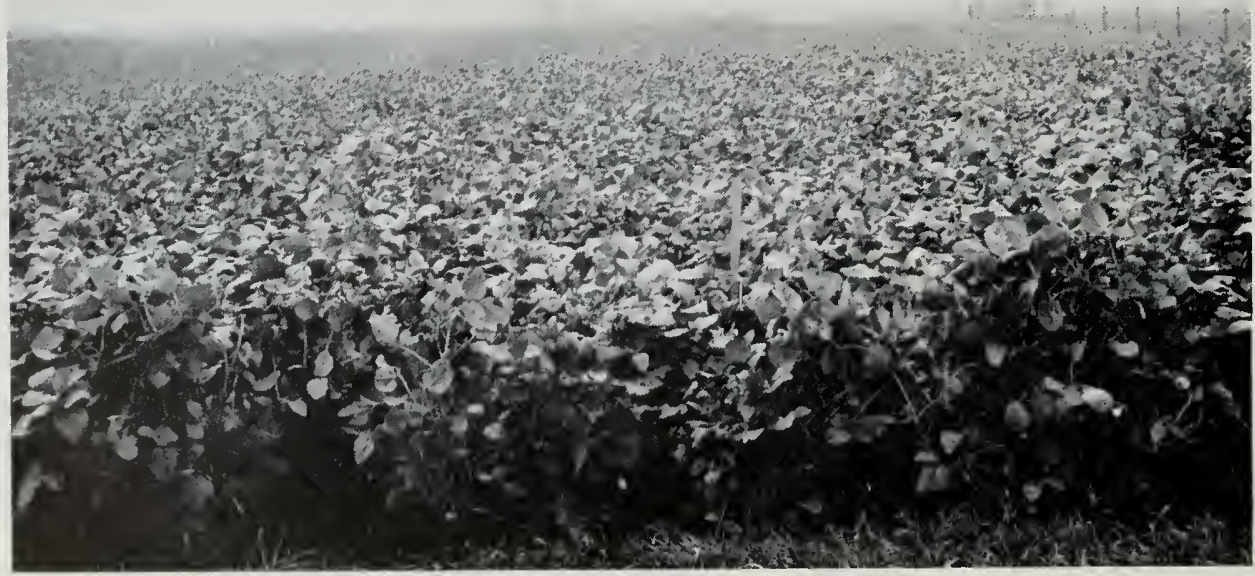




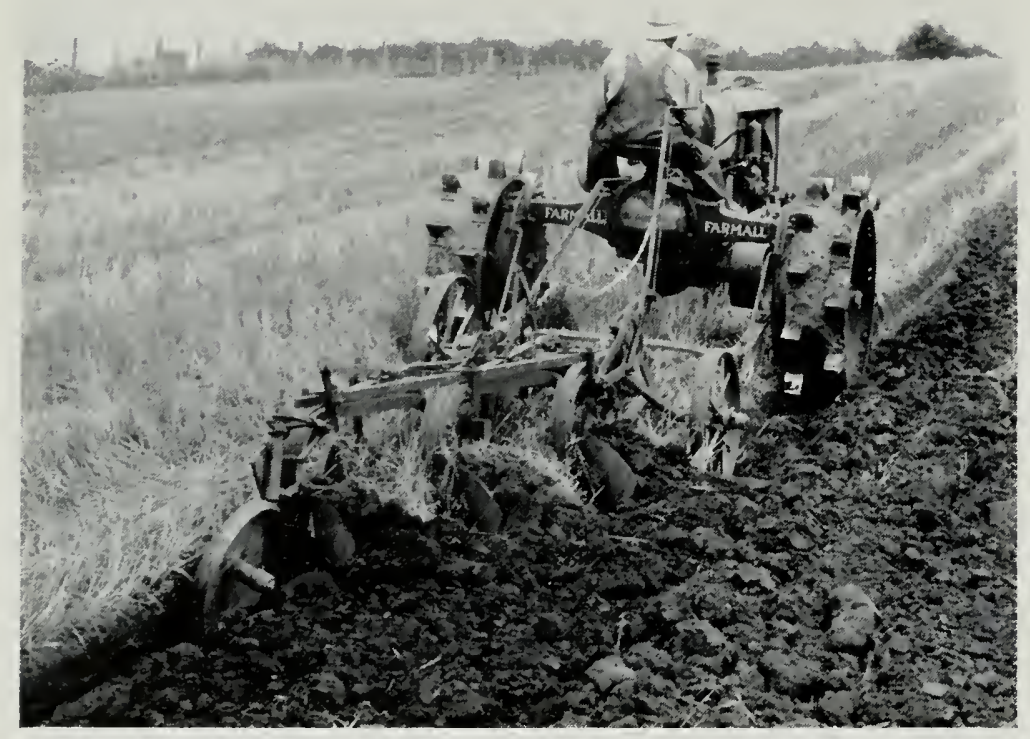

A modern plow of this type will turn ten to fifteen acres a day.

then, is to aid nature in providing the most favorable conditions for the growth of the plant. The first step in this process is to provide the infant plant with a good bed in which to grow.

There are generally three steps in preparing the seedbed, namely, plowing, disking, and harrowing. Plowing, which involves a turning over of the soil, is one of the first steps in seedbed preparation and is the operation requiring the most time and power. Disking digs up the soil. The land may be disked both before and after plowing. Harrowing pulverizes and smooths the soil. Disking and harrowing are both used as finishing processes in seedbed preparation. They help to kill weeds, one of the farmer's greatest enemies, and pulverize and level the land prior to planting.

Each of these operations may be done either with horses or with a tractor, and you may be asked to do some of this work.

Planting. In planting farm crops, the seed may be broadcast, it may Le drilled, or it may be checked. Seed which is broadcast is distributed rather evenly over the ground but is not in rows. The seed is then covered by harrowing or disking, which might be considered as putting the finishing touches on the seeding job.

Grain that is drilled is planted in rows. The rows may be anywhere from a few inches to over three feet apart. The drill drops and covers the seed in the same operation.

A track-type tractor pulling a disc harrow and a spiketooth harrow to firm and smooth the seedbed for crops.

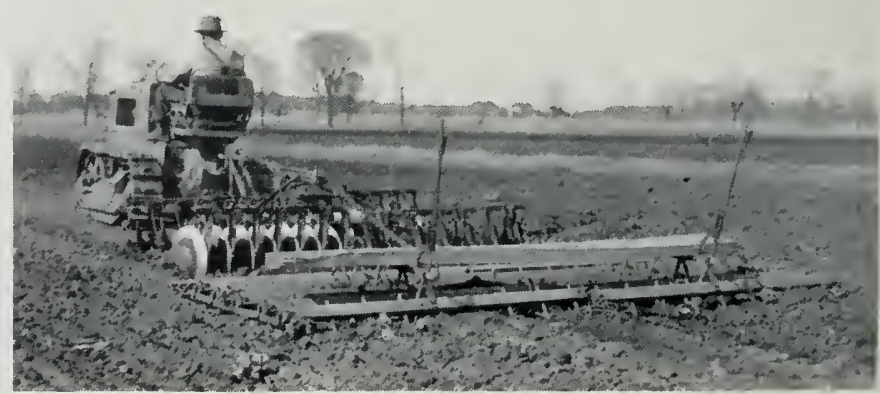


Corn is the only major crop in Illinois which is checked. Checkrowing means planting the crop so that it is in rows in both directions and can be cultivated both lengthwise and crosswise.

Cultivation. After the crop has been planted and starts to grow, it must be protected from some of its enemies. Weeds are the greatest enemies to farm crops,

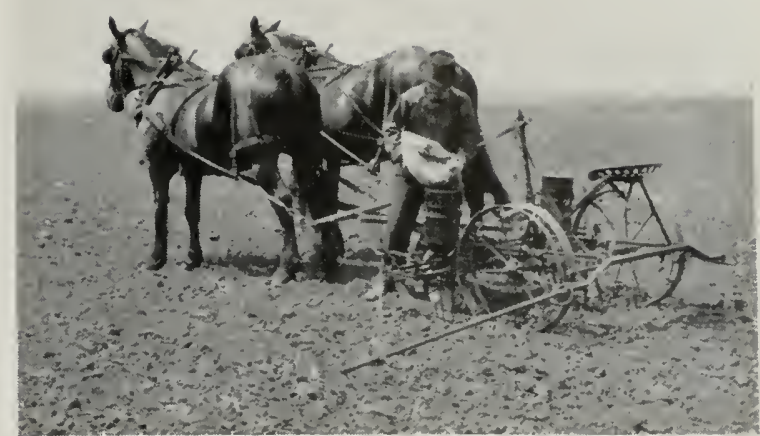

This farmer is using a two-row horse-drawn machine for planting corn. Fifteen to 20 acres a day can be planted in this way.

and cultivation is one means used to fight them. Any process which destroys weeds by disturbing their root systems as a result of turning over the soil is known as cultivation. Although the major objective of cultivation is weed control, it also pulverizes and loosens the soil.

Cultivation therefore takes forms varying from hand hoeing to cultivating corn with a four-row tractor cultivator. The following horse- or tractor-drawn implements are commonly used for the cultivation of farm crops: harrows, rotary hoes, and various types of cultivators.

The small-grain crops are normally not cultivated. They are broadcast or drilled in early spring and are harvested before weeds become a serious problem. The major cultivated crops in Illinois are corn and soybeans.

Before the complete mechanization of agriculture, cultivating corn with a two-horse cultivator was one of the first field jobs farm boys learned to do. You may be expected to cultivate corn with either tractor- or horse-drawn equipment and you should be careful to get the weeds but not to plow out or cover up any of the corn plants.

Harvesting. Here is a true test of your physical stamina and ability to "take it." Harvesting operations on the farm involve some of the heaviest physical labor you will encounter.

Much corn is now cultivated with motor cultivators. If you should operate such a machine, the farmer will expect you to be careful not to plow out or cover up the small corn plants.

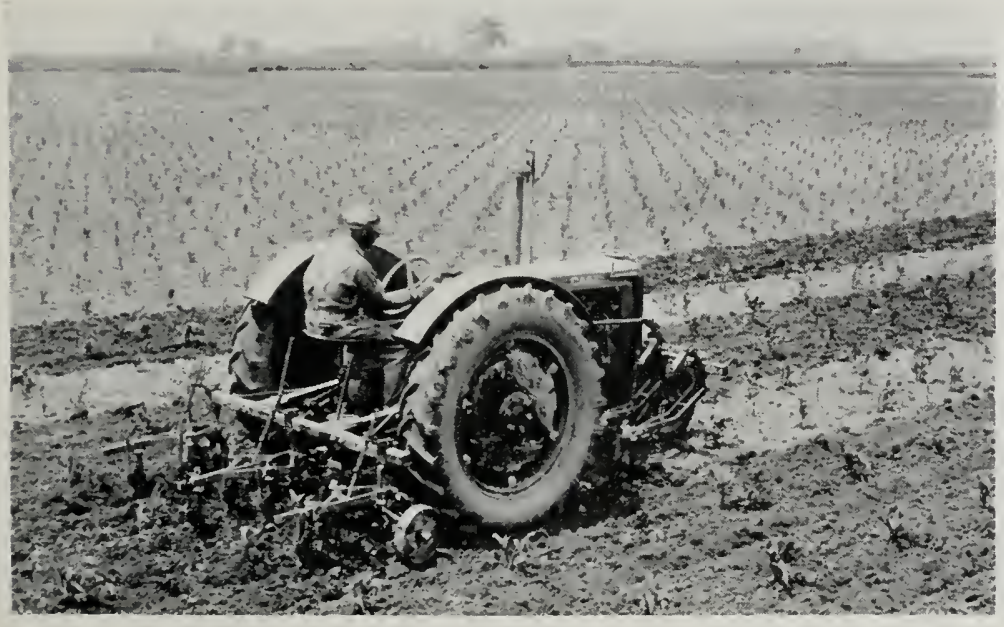


Small grains and soybeans are harvested in one of two ways. Either the crop is combined (pronounced kom' bind), which includes cutting and threshing in one operation, or it is cut with a binder, put in shocks to dry, and finally hauled to a threshing machine to be threshed. Shocks are the piles of upright sheaves of grain you perhaps have seen on farm land during a drive through the country. Most of the wheat and soybeans grown are combined. However, in livestock areas, more of the small grain is threshed because the farmers need the straw. You will probably be on the farm during small-grain harvest. In that case you may be asked to

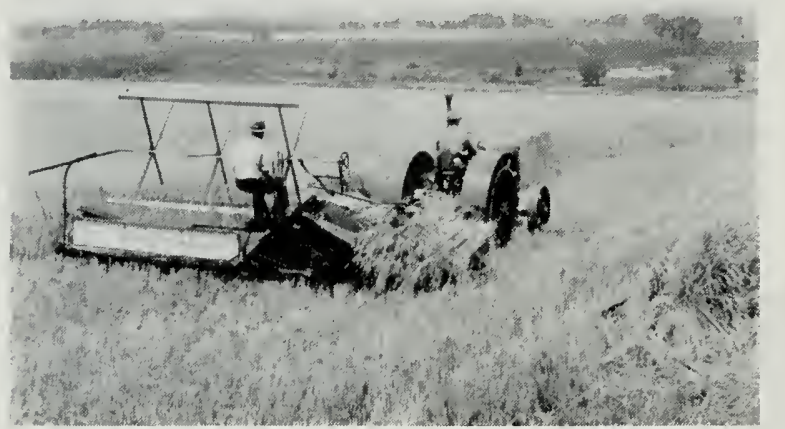

This farmer is cutting his wheat with a tractor binder. The bundles are dropped in piles from the carrier for the convenience of the "shockers."

Shocking wheat is hard work and the weather is likely to be hot. Try to set the bundles up so that the shocks will stand.
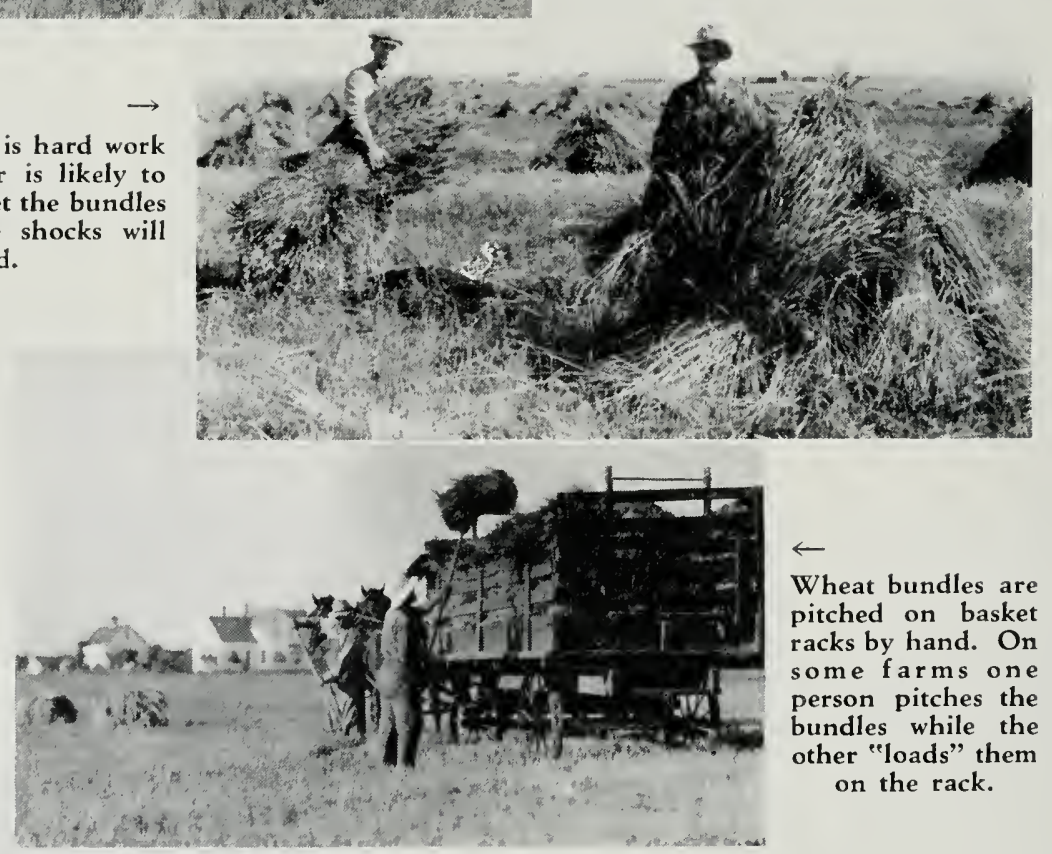

Wheat bundles are pitched on basket racks by hand. On some farms one person pitches the bundles while the other "loads" them on the rack.

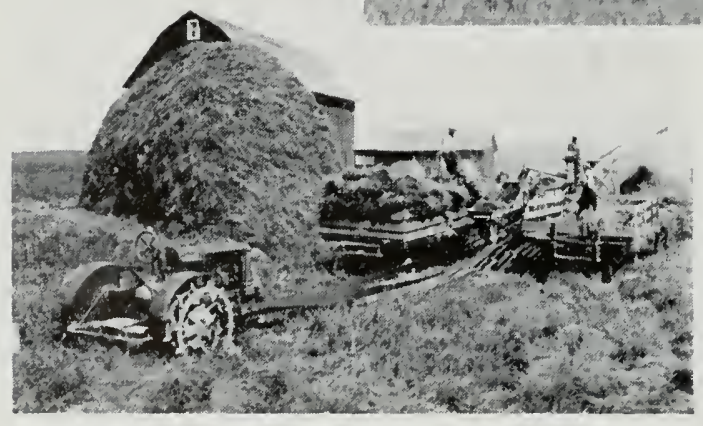

Rack wagons are being used to haul wheat from the shocks to the threshing machine. The grain is delivered into a box wagon, and the straw is blown through the long tube onto the straw stack. If a combine is used (see page 42) it replaces both the binder and the threshing machine.

PAGE 34 
shock grain, to pitch bundles, or to haul threshed grain away from the machine.

Corn may be harvested in one of several ways, including cutting it with a corn binder and shocking it for shredding later, or picking it by hand or machine from the standing stalk.

Hay harvest requires a great amount of physical exertion. The hay may be cut, cured, and put in the barn loose, or it may be baled out of the field. In either instance, a considerable amount of hand labor in hot weather is necessary.

Harvest Dangers. There are a number of precautions which you should observe when helping to harvest crops.

First of all, do not overwork yourself. Hay and small-grain harvest occurs during the hottest part of the summer. Take your time. Watch the experienced hands so you may develop methods of work that require the least exertion. Do not get too hot. Heat prostration may keep you from working during the rest of the summer and may even cause permanent injury. By developing skill at the job, you can gradually increase the amount of work you can do in hot weather.

You may be asked to care for and operate various machines. While machine operation may require less physical labor than other harvest jobs, it carries with it greater responsibility. A combine, a tractor, or a binder is a complicated machine and represents a large investment on the part of the farmer. If you are given the responsibility of operating machines, be sure to follow instructions carefully. If instructions are not complete, or you do not understand them, do not hesitate to ask questions.

Finally, you must always keep in mind the dangers in connection with the operation of machinery, particularly power-driven machines. Every year thousands of farmers and farm workers are injured or killed when working around such machines. It is not that the machines are dangerous, but that the workers endanger themselves as a result of carelessness, fatigue, or neglect. More will be said about some of the dangers in connection with farm work in Part 9. 


\section{6) \\ Farm Equipment and Buildings}

\section{Learn to Identify}

During the past two decades Illinois agriculture has become highly mechanized. To be successful, a farmer must know how to use a wide variety of equipment and machinery, as well as to perform many diverse jobs. The use of much of this equipment is so commonplace to the farmer that he may take it for granted that everyone is as familiar with its appearance and use as he is. Although you may already know a rather large number of pieces of equipment there are some you may be asked to operate that will be entirely new to you. It would be well for you to learn now to identify the various buildings and items of equipment on a farm and to know for what purposes they are used. That knowledge, together

You can increase your usefulness by learning the names of these tools and their purposes. They are identified as follows: 1, barn broom; 2 , long handle shovel; 3 , hoe; 4, garden rake; 5, pitch fork; 6 , scythe; 7 , shovel; 8 , spade; 9 , saw; 10, ax; 11, hatchet; and 12, hammer.

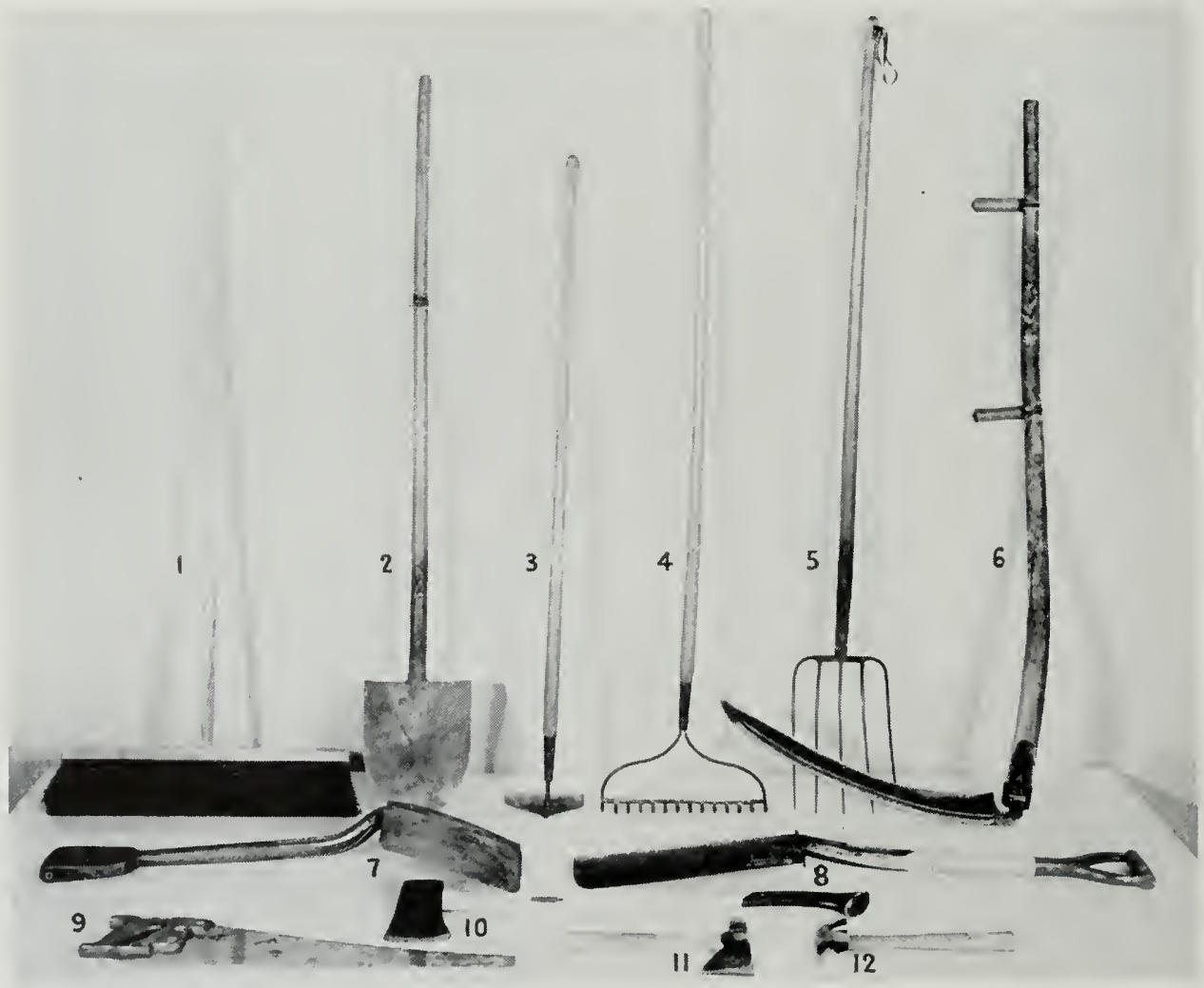




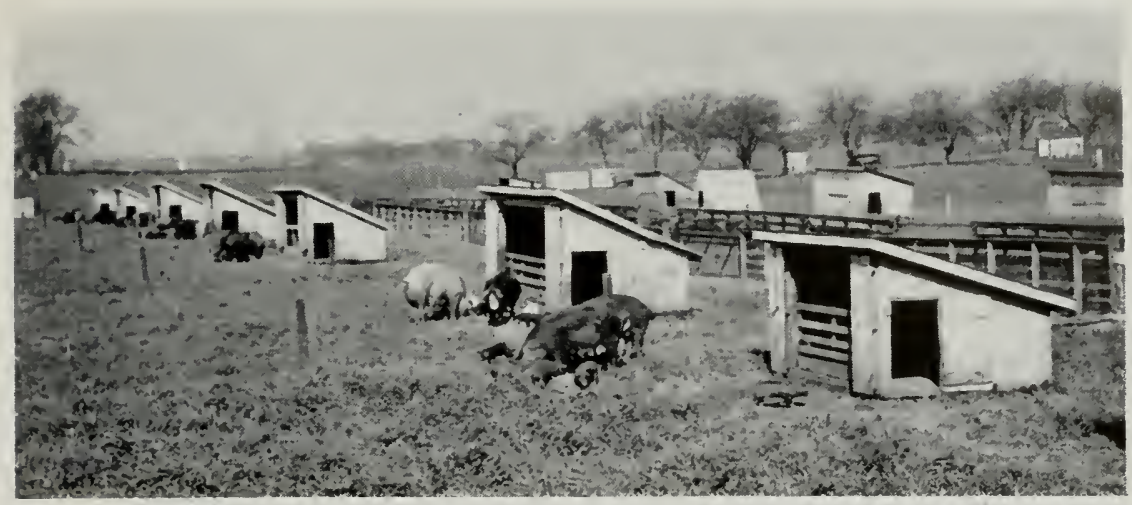

The most successful hog producers use movable hog houses so that the pigs may be kept on clean pastures.

with supervision from the farmer, will help you to master their use much more readily.

For convenience in presenting the material, the items have been divided into three general groups: small tools, buildings and their equipment, and miscellaneous equipment.

The items described here fall far short of making up a complete list, but they are the most common ones found on the majority of farms. The amount of equipment on individual farms varies immensely, depending upon the type of farming done and the interest of the farmer. Some farmers have a completely equipped farm shop in which they are able to do practically all of their own mechanical work; others have nothing more than a few small tools.

\section{Small Tools}

You have no doubt used a number of the tools shown on page 36. Make it a special point to learn to identify those which are new to you and to learn their use. If some of the tools are available to you at home, you may want to practice using them.

You can help save time-the factor that is so vital in this war emergency-by keeping things in their proper places and seeing that they are always in good condition. Then no time will be lost looking for misplaced items, or in using tools made ineffective by careless handling.

The interior of a barn showing stanchions for dairy cows. The cows must be fastened in the stanchions before each milking and released again afterwards.

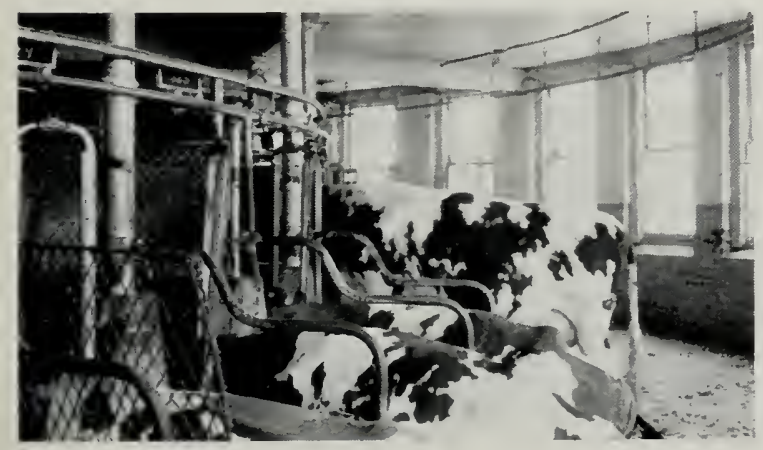

Learn where every small tool is expected to be kept. When not in use, see that it is in that place. Similarly, when you finish using a piece of equipment, put it where it belongs so that you and everyone else on the farm will know where to find it when it is next wanted.

Do not use tools for purposes other than the ones they are intended to serve. The hatchet and 


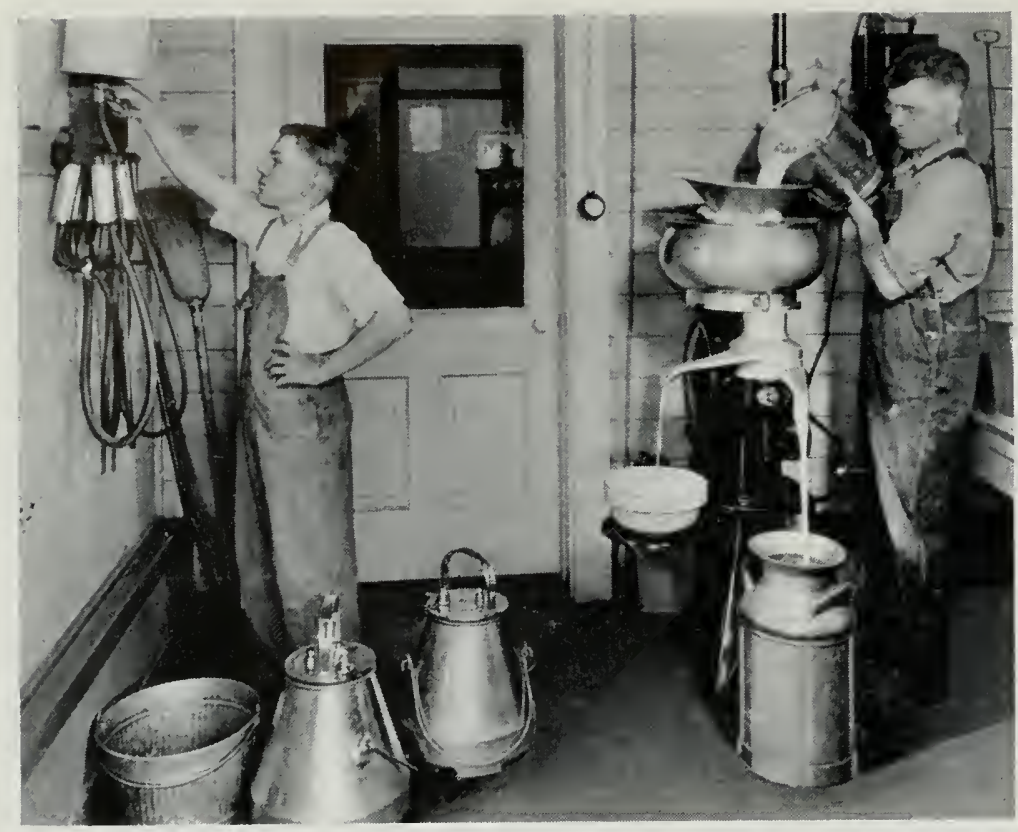

The milk is poured through the strainer into the cream separator, which sends the cream into the crock and the skimmed milk into the can. All milk equipment must be kept very clean by thorough washing and sterilizing.

ax should not be used to cut nails or wire, and handles of the various tools should not be used as prying rods. Tools are usually broken or ruined by being incorrectly used, or by being used for something for which they were not intended.

When you are through using a tool, be sure that it is in good condition before putting it away. Make sure the spade is properly cleaned, dried, and oiled. Each tool should be in ideal condition for the next time it is needed.

Finally, before using any equipment which is new to you, ask the farmer for instructions in regard to using and caring for it.

\section{Buildings and Equipment}

The farmer refers to his buildings and parts of them in his everyday language, and may very likely take for granted that you know to what he is referring. You should therefore be familiar with the more common farm buildings and the equipment which is ordinarily a part of them.

You will immediately see that the names of most farm buildings denote their use. However, don't be fooled by the name "milk house." It is not the building where the cows are milked but rather the building in which the milk is cooled and kept.

The farm machinery will be housed in a machine shed when not in use, unless the farmer is careless.

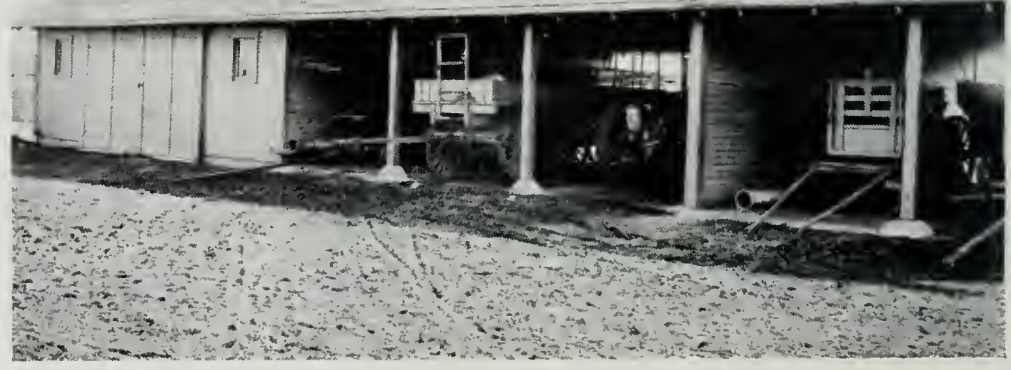




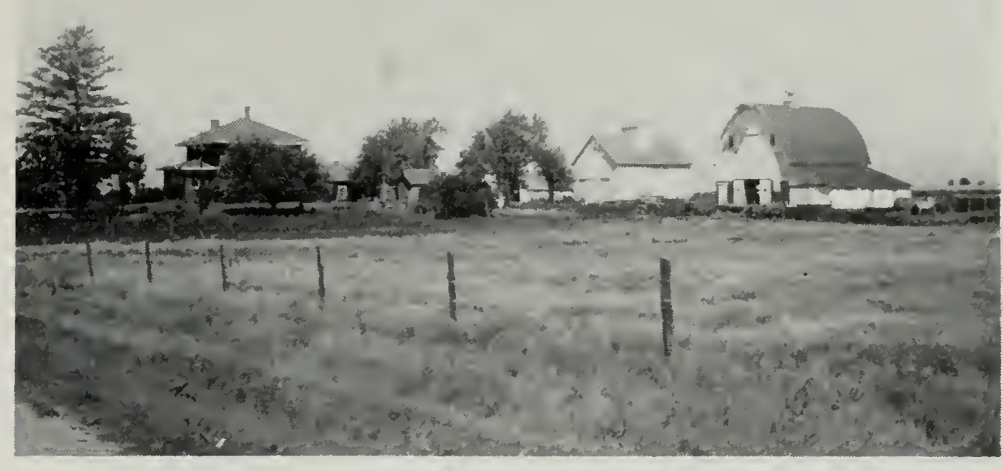

A well-organized farmstead-house, garage, windmill, machine shed, corn crib, and barn.

You cannot always identify a farm building by any one characteristic. The buildings vary tremendously in size, shape, color, and the materials of which they are constructed. The above illustration will give you a general idea of the common farm buildings, but you will of course have to become personally acquainted with the buildings on the farm where you work.

\section{Miscellaneous Equipment}

In addition to the small tools and the buildings pictured, there are numerous other items of equipment on many farms. Some of the more common of them, such as stanchions, cream separator, milking machine. self-feeder, and individual hog houses, are shown in earlier pictures.

During your stay on the farm you will be expected to use or operate a number of these pieces of equipment. Some of them are extremely simple; others are somewhat complicated. The general suggestions given for the use of small tools apply here-make it a rule to follow instructions or to ask for information when in doubt.

\section{Your Opportunities and Responsibilities}

While recognizing the opportunities that use of the tools, equipment, and buildings of a farm offer you for developing a variety of manipulative skills and practical, specialized knowledge, do not overlook the responsibilities that you must ascept with them.

Take care of the tools and equipment you use; they are especially precious items now, when many of them would be very difficult to replace. Breakage may cause serious delays, loss of time, and reduced production.

When you use a new tool or piece of equipment try to find our for what it is used, how it is used, and why it is used in that manner. It is essential that you learn the what and how. Learning why clarifies the what and how so much that you, as a conscientious worker, should never pass up the opportunity to add this to your knowledge. Of course you can find out a great deal for yourself through experience but experience is often a slow teacher. Supplement and add to your experience by looking to your employer or fellow workmen for advice and supervision, and don't be afraid to ask for that assistance. You should not be ashamed because you do not know certain things; you should be ashamed only if you do not learn them when you have the opportunity. 
The final step in seed bed preparation. This five-section harrow is leaving the land in good condition for planting.

7)

\section{Operating Farm Machinery- Your Responsibilities}

\section{Kinds of Farm Machinery}

In the previous unit, farm buildings, small tools, and equipment were discussed. In defining farm machinery and farm equipment, it is difficult to draw a distinct dividing line between the two. However, for the most part, the large items of machinery which are used in field operations are included under farm machinery.

Since World War I agriculture has become highly mechanized; in fact so much so that many farmers keep no horses but rely solely on mechanical power. If you perform any of the field operations, you will probably be handling some of the farm machinery.

Wheat is being drilled here with a tractor drill. Note the straight marker track by which the farmer is steering the tractor.

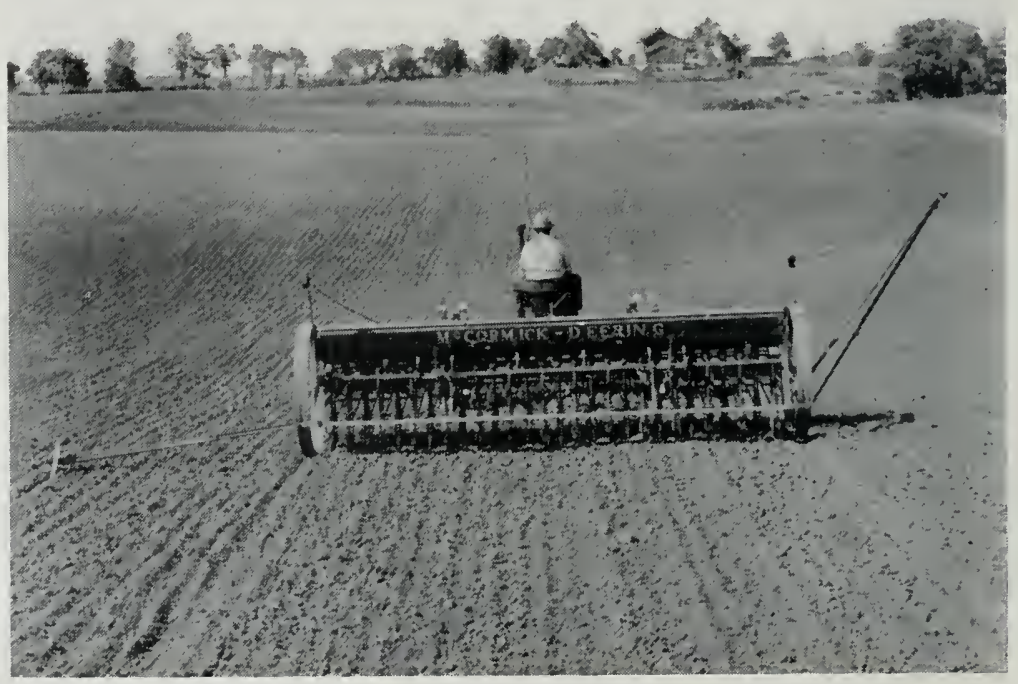




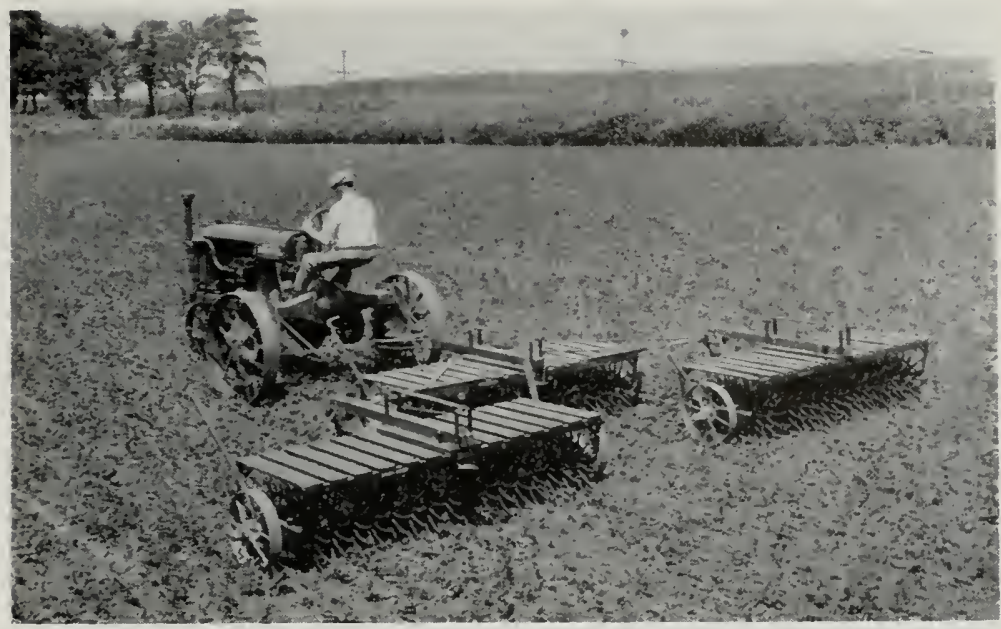

A large area of soybeans (drilled solid) can be cultivated in one day with three rotary hoes and a tractor.

Farm machines vary from the most elementary types to some that are extremely complicated, such as combines and corn pickers. Many of these machines represent large investments. Many of them can be seriously damaged by improper care and handling. Many require skilled and experienced operators. The operation of others is relatively simple and can be mastered in a short time. Most farm machines must be properly adjusted if they are to operate effectively.

You can learn to care for and operate these machines only by experience. If you have some mechanical ability and experience, it will prove valuable. Reading about machines will not qualify you to operate them, but it will enable you to identify them and to know the purposes for which they are used. You will recall that in the unit on crop production, crop operations were grouped into four categories: seedbed preparation, planting, cultivating, and harvesting. While farm machinery is not classified

\section{PAGE 41}

A horse-drawn cultivator is used on some farms for cultivating corn. This is a two-row machine, but you may get your start on a one-row outfit.

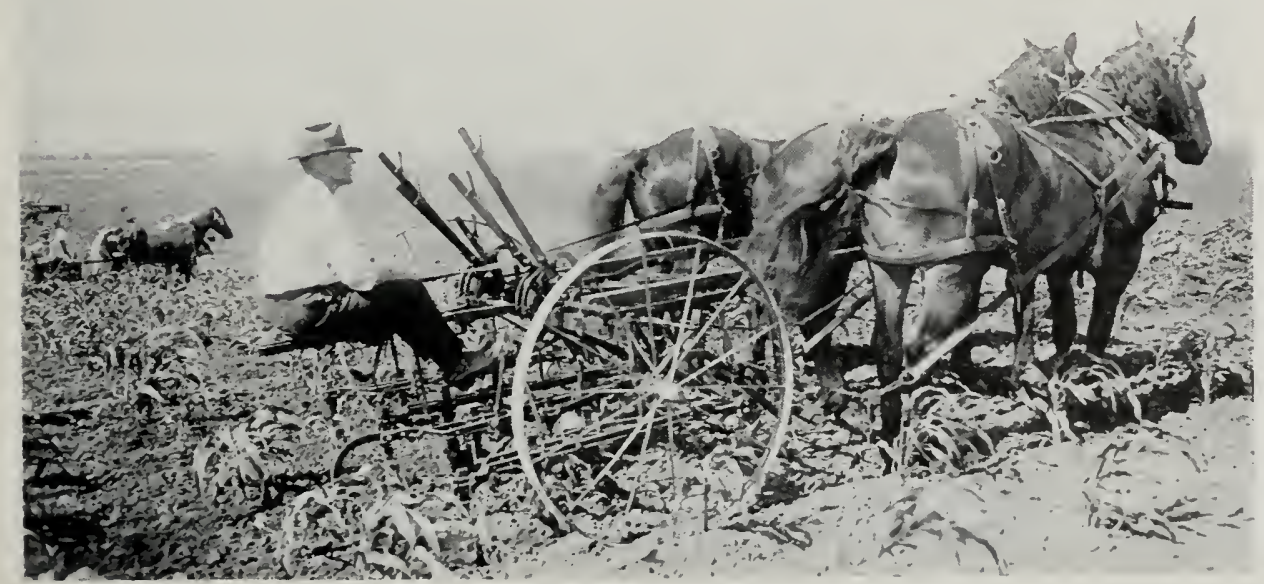




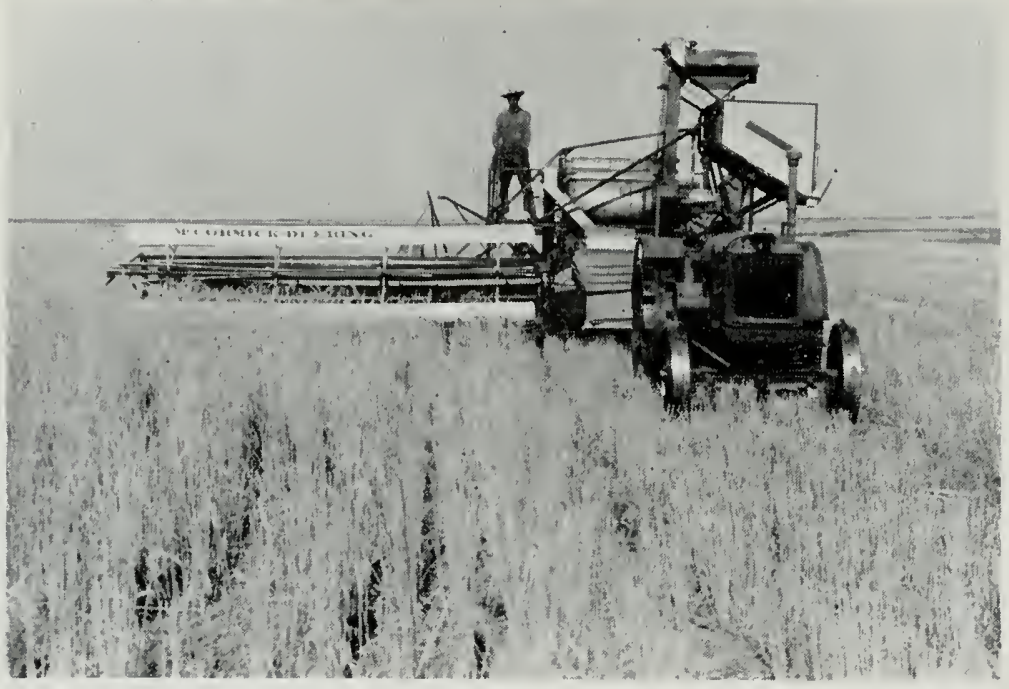

Cutting wheat with a combine saves a lot of labor. The combine replaces both the binder and the threshing machine. The grain is collected in the tank, to be dumped into a wagon or a truck, and the straw falls on the ground.

on just that same basis, it is well to keep this use classification in mind when studying the machinery pictures.

\section{Farm Machinery and Wartime Production}

Mechanization of Illinois farms has greatly reduced their need for man labor. Since manpower may eventually determine the outcome of the war, you can readily appreciate the importance of mechanical equipment in maintaining agricultural production.

Nevertheless, farm machines are being rationed. Only 20 percent as much new machinery as farmers purchased in 1941 will be available to them in 1943. A farmer must obtain a permit from his rationing board before he can buy certain new machines. It may be somewhat difficult to obtain repair parts. This makes it extremely important for every farmer to take the very best possible care of all his machinery.

The field silage-cutter, shown below, delivers the chopped corn into the wagon. This is much easier than loading bundles onto wagons and hauling them to a stationary cutter.

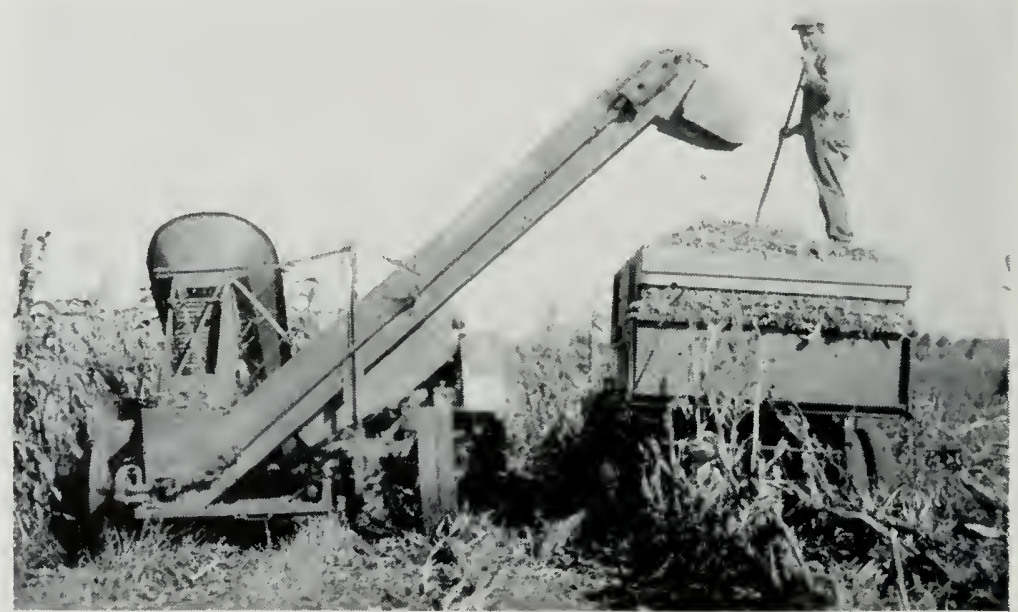


Scooping oats on the sunny side of the barn will warm you up. You may also get a blistered back if you leave your shirt off too long at one time before you get a good tan.

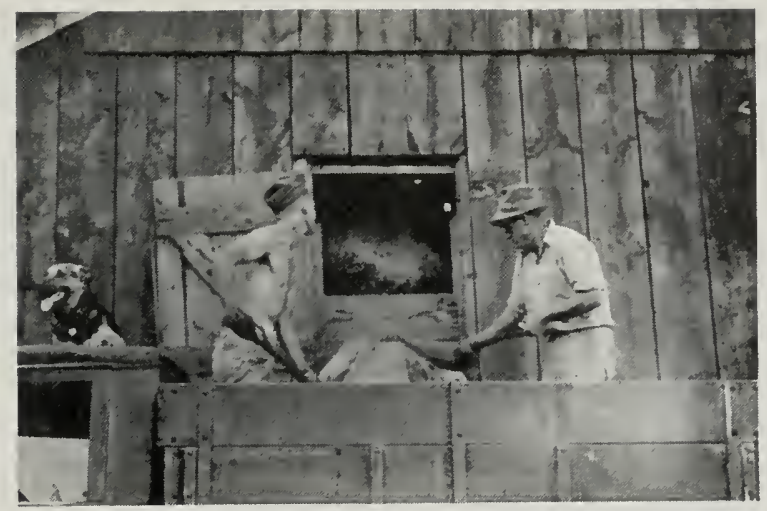

Now just what are your responsibilities if you are asked to operate the machines?

1. Be sure the machine is properly adjusted; get the farmer to help you in adjusting it.

2. Do not attempt to learn by experimenting with the machine. You risk serious injury to yourself and damage to the machine if you make a mistake.

3. Obtain complete instructions concerning the operation of the machine. If you want to learn, ask questions, and do not hesitate to request that someone supervise your work until you are confident you can perform it yourself. It is much safer to expose your lack of knowledge than to hide it and make a costly error.

4. Always observe all precautions and safety rules in operating farm machinery.

Here is a chance for you to get some valuable mechanical experience. Make the most of this opportunity, but keep in mind that first and foremost your job is to help the farmer produce food and feed. Everything you do must help him in that effort.

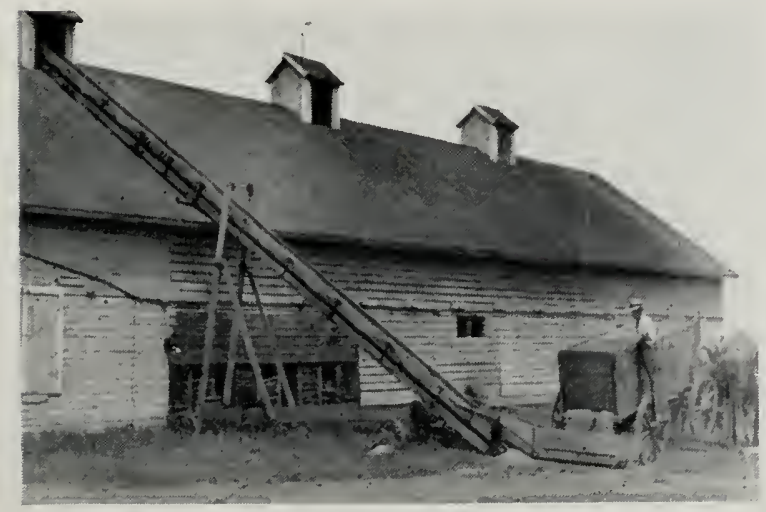

A grain elevator will put the oats in the granary as fast as two men can scoop. This farmer won't be too tired to enjoy his dinner. 
8)

\section{Special Types of Work and Odd Jobs on the Farm}

\section{Fruit, Vegetables, and Canning Crops}

The discussion thus far has assumed that you will live and work on either grain or livestock farms since farms of this type make up a large part of the agricultural industry in the Middle West. There are, however, in Illinois and in adjacent states, a considerable number of specialized fruit and vegetable farms and there are other types of farm work at which you may find employment during the summer months.

\section{Commercial Vegetable Farms}

Commercial vegetable production is an important industry near most large cities, and there will be an opportunity for many boys to find summer work on "truck farms" near Chicago, Peoria, Quincy, Rockford, East St. Louis, and other cities. In comparison with grain and livestock farms, vegetable farms are relatively small. Since much of the weeding, harvesting, and preparation of crops for market is hand work, a tract as small as 30 acres may furnish enough work for several persons during the summer months.

Many farmers who live near cities transport workers to their farms by truck each morning. They pick them up at a point that can be conveniently reached by streetcar or bus from the city, and return them to this place when the day's work is finished. This enables the workers to live at home. Other vegetable farmers furnish room and board to their summer help. If there are a great many workers, the sleeping quarters may be bunk houses of various kinds or even temporary facilities in store houses or barn lofts.

This crew is pulling tomato plants which will be reset for commercial production. This is a good job for city boys.

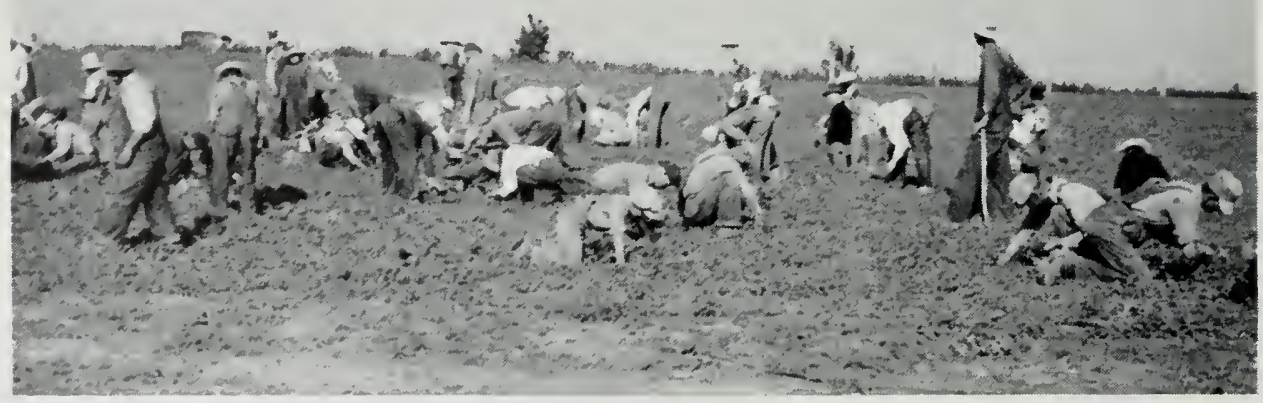




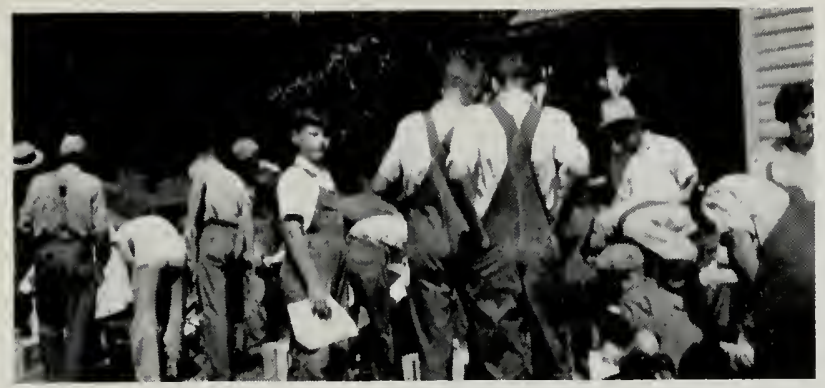

These boys and girls are being trained to pick tomatoes. They will learn how to tell when the fruit is ripe, and will be shown how to pick without injuring either the fruit or the vines.

In some respects it will be easier to learn to work on a vegetable farm than on a general farm since there will be fewer operations to master and several persons may work in one crew under the supervision of the farmer or an experienced hand.

\section{Know Your Vegetables}

About fifty different kinds of vegetables are grown in Illinois-sometimes as many as twenty varieties on one farm. Learn to recognize all the more important vegetables before going to work on a vegetable farm. Pictures in seed catalogs will be helpful. If you visit a large market where vegetables are received from southern localities early in the season, you will be able to see the different vegetables themselves. Not only should you be able to recognize the mature vegetables-those that are ready for market-but you should also learn what the plants look like when they are just young seedlings. This should help you avoid pulling up vegetable plants along with the weeds when you are detailed to do hand weeding. You may refer to botany text books for pictures of many vegetable seedlings, or you may plant varieties of vegetable seeds in a shallow box of soil at the school house, and study the resulting seedlings.

\section{Nature of the Work}

On vegetable farms where many kinds of vegetable crops are grown, the summer work includes: (1) preparation of the seedbed, (2) planting,

Hand-hoeing is one of the odd jobs you will probably do in connection with garden work.

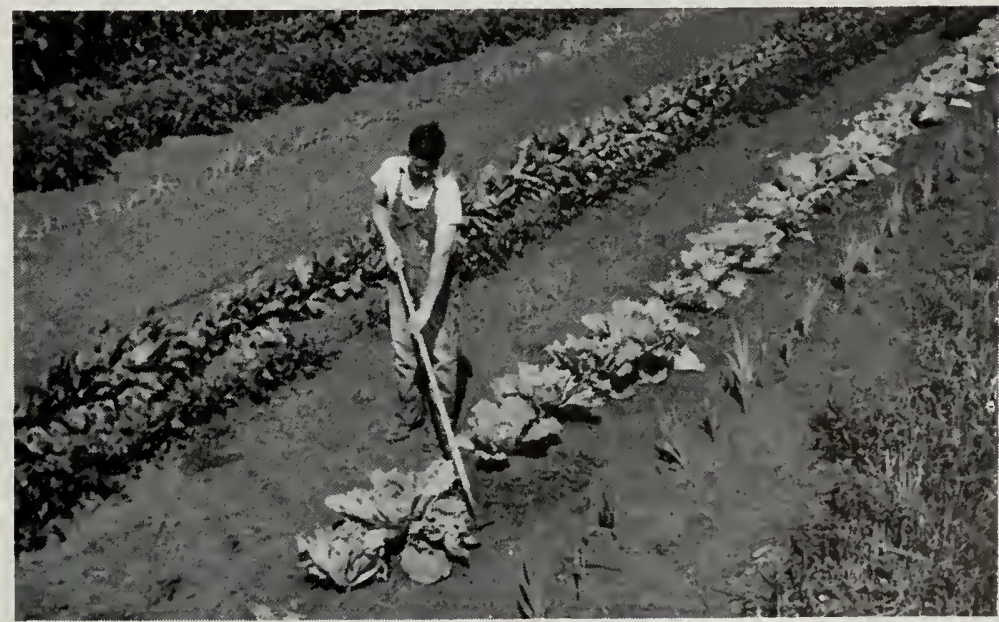




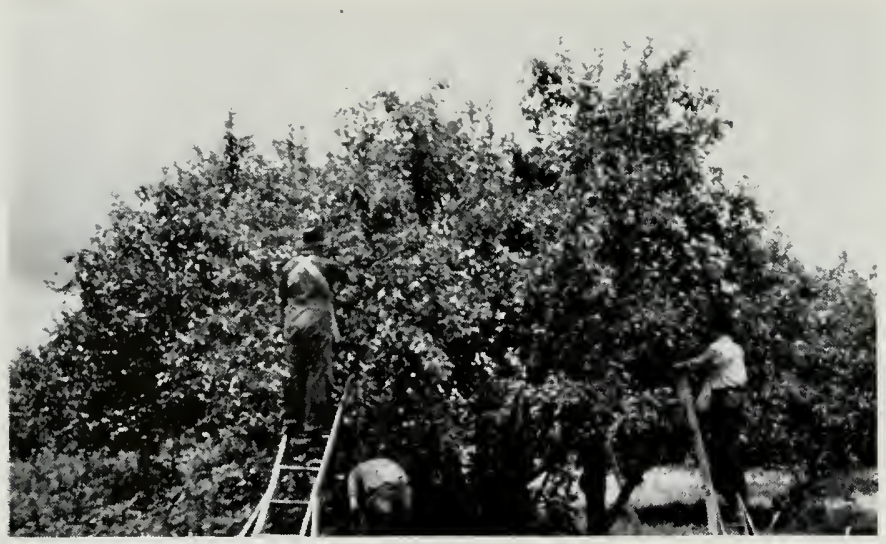

Tall ladders are needed to pick apples from trees of this type, and only strong boys can move them about for efficient picking.

(3) cultivation and other care of crops, such as weeding, and spraying for control of insects and plant diseases, (4) harvesting, and (5) preparation of vegetables for market, which includes grading, bunching, washing, and packing.

The soil is prepared with the same kinds of tools used for grain crops, with the addition of a meeker harrow, or a "float," which puts the finishing touches to the seedbed. Planting is done principally with single-row garden seed-drills pushed by hand, or with multiple drills drawn by garden tractors. You may be asked to operate either type of machine. Cultivating, too, is done by hand-pushed or tractor garden cultivators. Hand weeding of such crops as onions, beets, carrots, and parsnips is a job you are likely to encounter on any vegetable farm. Spraying of potatoes, cabbage, cucumbers, etc., for the control of insect and disease enemies is usually accomplished with power sprayers drawn by horses or tractors. Preparation of the spray materials is a very responsible job.

Vegetable crops must be harvested at just the right stage of maturity in order to meet the market requirements. They must be graded, bunched, and packed for market with great care. To do a good job, you will have to follow your employer's instructions very carefully.

\section{Commercial Fruit Farms}

On fruit farms, a large amount of extra help is needed for harvesting the crop. The harvest season on a fruit farm producing only one or two kinds of fruit may be of short duration (two or three weeks) whereas on farms producing a wide variety of fruit it may last all summer. Facilities for camping in cabins or tents are provided on some farms where large numbers of fruit pickers are needed for a short time.

Berry-picking does not require much muscle, but is a tedious job and requires care and perseverance. Since it is usually paid for as piece work, an industrious and experienced worker can make very good wages at it. Apple picking, on the other hand, runs into real work before the day is over. It requires the handling of long ladders if the trees are large, and the sacks filled with fruit get heavy to hold. Picking cherries 
has its advantages over the other fruit jobs. The trees are smaller than apple trees, step ladders are used, and the picking receptacles are not heavy to handle.

\section{Cannery Crops}

There are many farms on which a large acreage of one kind of vegetable may be grown for commercial canning. The harvesting of some of these cannery crops requires a great amount of labor. Asparagus farms need many extra hands to help cut the plants. If the weather is warm, an entire field must be gone over daily for cutting as asparagus shoots grow very fast, and a shoot that is "just right" today may be worthless tomorrow. The asparagus harvest lasts about two months, but begins before school is out. Cutting begins early in the morning and ought to be completed before noon each day. In some localities your school schedule may be arranged so that some of you can be released for this morning work.

Peas, sweet corn, and tomatoes are other cannery crops of importance in Illinois.

The early peas are harvested just about the time that school is out, and are followed by the harvesting of the later varieties, and then by corn. The harvesting of corn from various plantings of different varieties continues for about six weeks.

The peas are cut, vines and all, by the same mowing machine used in harvesting hay. On some farms, special loading machines are used for getting the pea vines onto the wagon racks. These racks haul them to the "viner," which hulls out the peas and screens them into different sizes ready for canning. On other farms, the heavy, green pea vines have to be pitched onto the wagon-racks with pitch forks. This, as well as pitching vines from the rack to feed the "viner," is heavy work.

The sweet corn is "snapped" from the stalks and thrown into a wagon with the husks left on.

Tomato picking for the canning factory comes for the most part after the corn-canning season is about over. Special care must be taken to pick the tomatoes at the right stage of maturity in order to make a high-grade canned product. Repeated pickings are required; the field must be gone over and over as long as the canning season lasts, or until the vines are killed by frost. Lugging picking baskets of tomatoes across the field in gathering the crop is a real man-sized job.

\section{Living Conditions on Specialized Farms}

Living conditions for workers on fruit and vegetable farms differ from those on general farms where the worker lives with the farm family. On the specialized farms, several workers will probably be employed for the rush period and they will work in crews, sleep in bunk houses, and eat in a mess hall. Boys who choose this type of work must expect to do without many conveniences of the home and to come in contact with all sorts of persons since these crews are recruited from far and wide. You will be working with some who make a regular business of helping 
in fruit and vegetable harvesting-they start in the south in the spring and work up north as the season progresses. You should keep these facts in mind when deciding whether to work on a specialized farm or on a general farm.

\section{Odd Jobs You May Be Asked to Do Many Kinds of Odd Jobs on General Farms}

It was called to your attention earlier that all farmers have a wide variety of jobs to do. The dairy farmer is more than just a producer of milk-he grows large quantities of feeds for his herd; in this connection, he operates machinery that requires him to be a mechanic of some ability; in maintaining the farmstead, including the house, he must be a caretaker, a gardener, and a carpenter.

This wide variety of functions creates for a farmer a multitude of miscellaneous or odd jobs. Farmers refer to many of these tasks as "rainy-day" jobs, because they can be put off until weather conditions prevent field work. During the war, while farmers are short of labor and are trying to increase production, some of these tasks will be delayed or dispensed with in favor of more important operations. There are many other odd jobs, however, that must be done regularly.

\section{Odd Jobs About the Farmstead}

Garden work. Most farmers grow some of the vegetables which they consume. Gas rationing and food shortages may emphasize the importance of the farm garden in 1943. Garden work often involves a large amount of hand labor, and on many farms, planting, hoeing, and harvesting are all done by hand. Some farms have the gardens or truck patches so arranged that some of the work can be performed with mechanical equipment. Regardless of the farm you are on, don't be surprised if you are asked to work in the garden.

Care of the lawn. The farm is a home as well as place of business. If the farmer and his family are to enjoy life, they should have an attractive and comfortable dwelling place. The grass must be mowed, weeds must be kept down, and flowers and shrubs must be cared for. Most of the work in the garden and about the house will not require severe physical exertion. It will, however, require persistence and endurance, and is often tiring since you must work in a stooped or kneeling position. These jobs will add variety to the work on the farm, and most of them can be mastered in a short period of time.

Miscellaneous jobs. It would be impossible to name all the odd jobs which you may be asked to do. They vary widely from farm to farm. Dairy farmers may give the barns a thorough cleaning and whitewashing once or twice a year; other farm buildings may be cleaned at regular or irregular intervals. Livestock feeders haul all manure out of the feedlot at various periods. Numerous odd jobs of carpenter work and machinery repair will have to be performed from time to time, and emergency situations may call for you to perform a variety of other tasks. 


\section{Odd Jobs About the Farm}

Cutting weeds. Farmers perennially wage a struggle against weeds. Weeds compete with farm crops for the plant food and moisture in the soil, and if the weeds are not destroyed, crop yields are reduced. Some weeds account for much human discomfort and suffering as their pollen causes hay fever. It is highly important for the farmer to keep these wild plants in check.

Numerous methods are used for controlling weeds. The importance of cultivation for that purpose was discussed earlier. Cultivation, however, is not a complete control measure, so the farmer must often resort to pulling or cutting the weeds. This job must be done in the hottest summer weather, and it is hard work requiring a large amount of hand labor. Weeds growing along the road or in fence rows may need to be cut by hand with a scythe.

Frequently it is necessary to go through small-grain or soybean fields and pull out weeds. Small-grain crops are not cultivated, and if weeds infest the fields, cutting or pulling by hand may be the only alternative methods of control.

Even in the case of corn, cultivation is not one hundred percent effective. Very often certain noxious weeds must be cut or pulled out of the corn after the last cultivation. This job is usually performed in August, and at that time the sun is hot and the corn is tall. There is very little breeze in a cornfield. The corn leaves are sharp and may irritate the skin. The work is not severe physically, but it may be uncomfortable for the worker.

Building and repairing fence. On any farm where livestock is kept, it is highly important to have good, strong fences. Many farmers use temporary fences which must be moved each year or so. Some of the fences are permanent and must be repaired regularly. You may be asked to help dig post holes, set posts, stretch wire, fasten wire to posts, and do general fence repair work. Some of these jobs require hard physical exertion while others are relatively simple.

You will undoubtedly need some supervision when you first start out on these jobs. There is danger of injury in working with fencing tools and equipment, especially in connection with barbed wire.

\section{Odd Jobs Essential to Farm Success}

It is very likely that a farmer may call on you to help with a number of the jobs we have mentioned. While some of these may become monotonous and try your patience, remember that many of them are just as essential to the farmer's success as are the major assignments in caring for livestock and producing crops. Some farmers may feel that you can do these jobs with little supervision and thus relieve the experienced workers for the more skilled jobs.

Be prepared to help out with a number of these so-called "odd jobs." Do them with the same efficiency and willingness that you carry to the other tasks. 
9)

\section{Safety Measures}

\section{We Can't Afford Accidents}

In any type of work there are certain dangers. In this emergency our country cannot afford to lose the services of large numbers of people by death or injury from accidents-the contribution of each and every individual to our total manpower resources is too important.

Because of scarcity of materials for replacement and the impossibility of buying new machines and equipment, special care must also be taken to protect every essential article against damage. Everyone should feel a personal obligation to take extra good care of all machinery and equipment, both when it is in actual use and when it is idle.

Also keep in mind that any loss of livestock due to accident, injuries, or sickness will cut down production. Many casualties on the farm would not occur if various protective measures and services were as available to farmers as they are to city people.

\section{There Are Many Farm Hazards}

The great need for precautions on the farm can be illustrated by the following observations. ${ }^{1}$

"Farmers use a surprisingly large number of tools having cutting edges and high-speed shafting and belting, and many of these are poorly protected or guarded against contact with one's person. Complete protection is virtually impossible.

"Fal'mers are often far removed from any source of medical assistance, and considerable time is required to reach a hospital when necessary. Doctors are becoming less common in small rural communities, for they are establishing themselves in the larger centers where they can serve

1 Quotations and all data presented in this section are from "The Prevention of Accidents on Farms and in Jomes," Bureau of Igricultural Economics, U. S. Department of Agriculture.

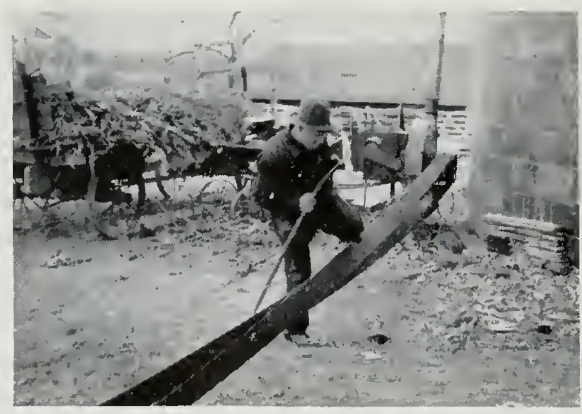

This man stands a good chance of being jerked into the pulley and killed. Don't climb through or over running belts. 


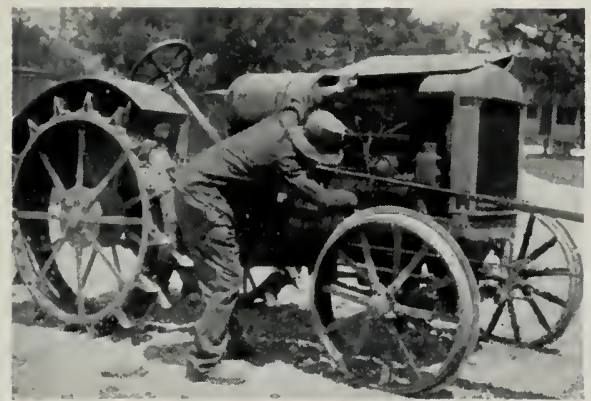

If this man should slip, that running belt might jerk his arm into the pulley and injure him. Never reach through or take hold of running belts.

a greater number of people. Less than a third of the injured farm people included in a study made in central New York State received help during the first hour following their accidents, and hardly two-thirds were cared for within six hours.

"Half of the accidents to farmers occurred in the barn and barnyardreal danger spots.

"Farmers sustain accidents most often to the upper part of the body.

"Farmers suffer from infection of wounds and need a standard antiseptic on hand at all times."

There are dangers and hazards associated with all types of work, and farming is, of course, no exception. Thousands of people are killed every year in traffic accidents, but this does not deter us from travelingit should merely make us more careful. So with farming, we need not fear accidents-we simply should be very careful to prevent them.

\section{Types of Farm Accidents}

By becoming familiar with most common types of farm accidents, it is possible for us to get a somewhat clearer picture of the precautions which need to be followed. You will recall that throughout the material presented to you and in the discussions of individual topics, the importance of carefulness and safety precautions have been emphasized. This has been done intentionally. Farmers will not tolerate workers who are deliberately neglectful and careless in regard to protecting life and property.

Always speak to a horse or mule to let him know that you are there before walking into his stall. Otherwise, his natural reaction may be to kick in surprise when you touch him.

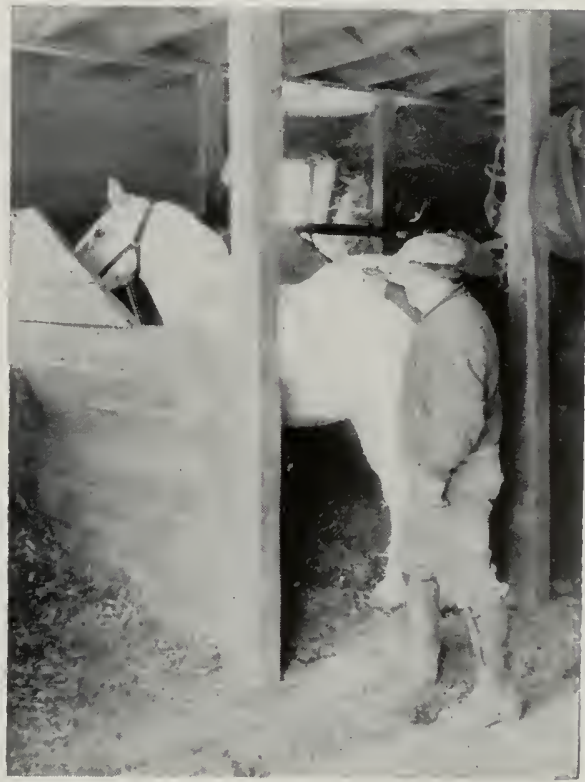




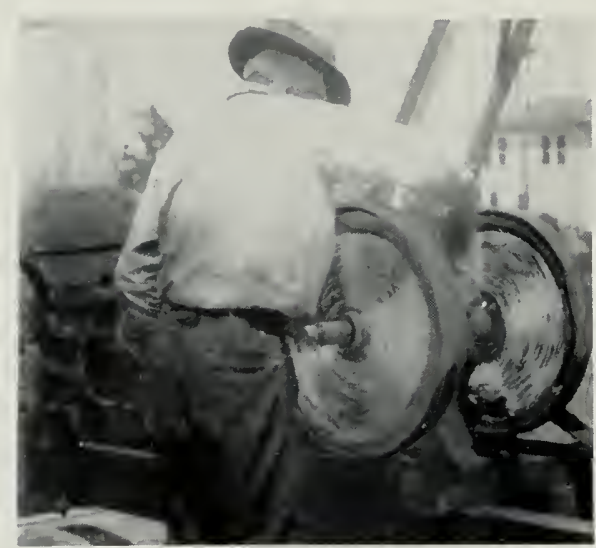

Many accidents occur when people carelessly reach over fly wheels to oil or adjust running machines. Don't take chances like the man in this picture!

The causes of 627 farm-labor claims under workmen's compensation during the years 1935 and 1936 were distributed as follows:
Cause of injury
Percent of injuries

Falls (all kinds) .............. 26.5

Animals ................... 15.0

Farm machinery . . . . . . . . . 11.8

Automobile ................. 9.6

Struck by objects.............. 12.4

Strains ................ 5.7

Cuts and bruises............. 5.6

Diseases and infection. . . . . . . . . . 2.7

Others .................. 10.7

Injuries caused by falls, animals, machinery, and being struck by objects are evidently the most common. To insure safety, do your work as the farmer instructs and use a reasonable amount of care.

This fellow is in a dangerous spot. Lone trees seem to attract lightning more than do trees in a forest. He would be much safer out in the middle of the field, and it is much better to be wet than dead.

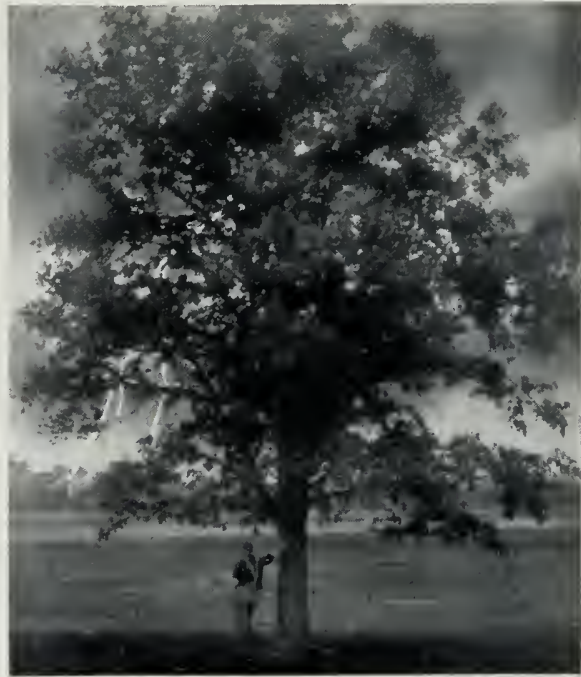


Here's a man who uses good sense. $\mathrm{He}$ doesn't let this bull's gentle appearance deceive him, but leads it with a strong staff.

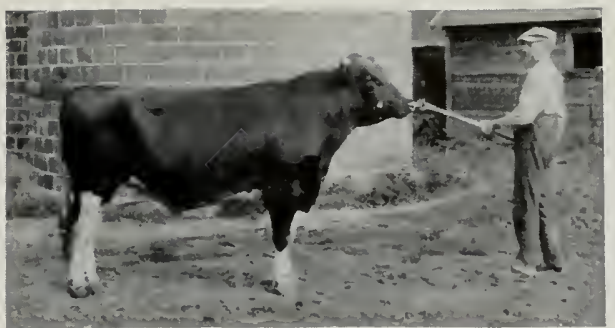

\section{Accidents in the Home}

The home is the place of a great many injuries and accidents. In 1940 the death rate per 100,000 holders of insurance policies was for motor vehicle accidents, 18.1 ; for home accidents, 11.7 ; and for occupational accidents, 6.2. Thus fatal accidents in the home ran a close second to fatal motor vehicle accidents.

In Minnesota during the first six months of 1940 accidents were responsible for 849 deaths, 40 percent of which were caused by home accidents. Since the home is the scene of so many accidents, it behooves us to be careful at all times, whether working about the farm or in the farm home. Play safe! Do not suffer injury because of a lack of knowledge or through carelessness. Learn good safety precautions and practice them daily.

\section{Danger of Fires}

Fire is a great danger on any farm. Many farms have no fire-fighting equipment or facilities available. Others, which are in an organized fire district, are so far from town that a fire may gain great headway before the fire truck arrives. Furthermore, most farms do not have a big enough

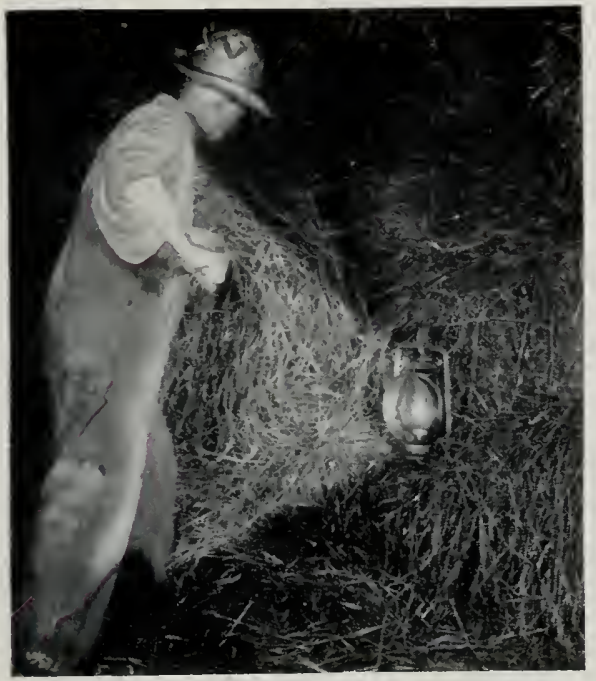

This farmer may start a costly fire and be severely burned himself. A lantern should be hung away from hay or straw, and in a place where cows or horses can't turn it over. 


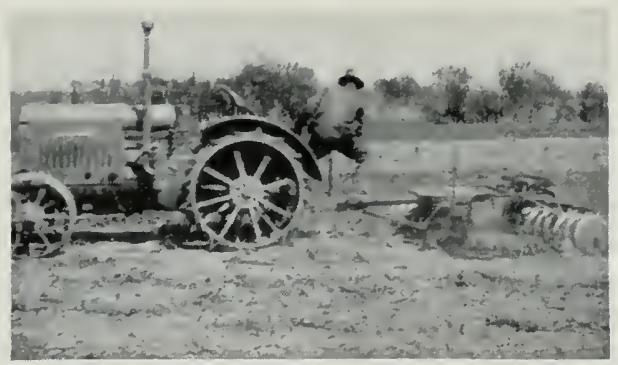

\begin{abstract}
Always stay on the tractor while it is moving Climbing back from a moving tractor to adjust something is flirting with death.
\end{abstract}

water supply to fight or control a large fire. Once the blaze gains a good start, the most that can usually be hoped for is that it can be kept from spreading to other buildings.

Many of the articles stored in farm buildings, and often the buildings themselves, are constructed of very inflammable materials. Hay and straw stored in the barn burn rapidly and fiercely once they are ignited. Most of the buildings are constructed of wood which is the most combustible of all building materials.

\title{
Safety Precautions
}

Now that some of the dangers, losses, and hazards that exist or occur on farms have been pointed out, let us summarize some of the precautions which we as individuals can and should observe:

1. Falls are one of the most common causes of injuries. When working where there is possibility of a fall, work and act slowly, carefully, and cautiously. If you are trusting some structure to hold you, make sure it is strong enough to support your weight and be sure of your footing.

2. In using tools, beware of sharp edges, make sure the tool is in good operating condition, and use the tool only for what it is intended.

3. In operating machinery be sure each machine is properly adjusted and in good operating condition. Never attempt to adjust or repair a machine that is in operation. Keep your hands and your clothing away from moving parts. Follow instructions. Never take unnecessary chances.

When unhitching a team be sure both horses are unhitched before leading them away. Leaving one tug hitched to the wagon can start a wreck. Have a regular system for unhitching the team.

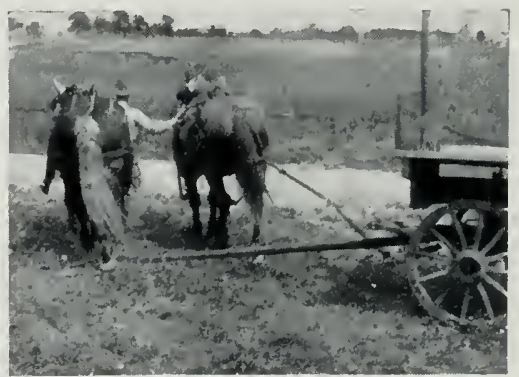


There's trouble ahead for this man. The mower is in gear with horses hitched to it, and he is down in front of the mowing machine knives.

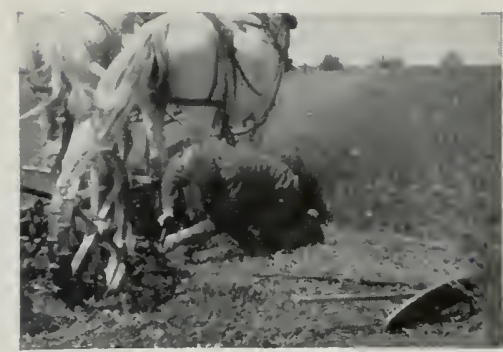

4. When working around farm animals of any kind, be extremely cautious until they become accustomed to you. Almost any of them may be dangerous to strangers. Leave the care of all male animals to the farmer, for the male of any species is likely to be dangerous. Livestock, particularly bulls, are the cause of many injuries and deaths.

5. Fire is a great hazard on all farms. NEVER SMOKE IN OR AROUND ANY FARM BUILDING. Be careful with lamps and lanterns. And don't carry loose matches or strike them to see your way around in the dark.

Most of these and other safety precautions you already know. So have other people known them who have caused thousands of fatal accidents-they thought the accident wouldn't happen to them, but it did. So GOOD JUDGMEN'T and the good sense NOT TO TAKE CHANCES are absolutely necessary in the prevention of accidents.

The principal difference between farm dangers and hazards and those of industry is that there are not so many remedial and corrective measures available to farmers. PREVENTION is therefore more than ever important for them. Know what you should do and how to do it before you start. 


\section{0)}

\section{A Day on a Farm}

\section{Farm Life Is More Than Just Work}

Getting used to the change from city life, living with the farm family, and taking part in rural community affairs are all as much a part of farm life as the work to be done.

Let us look in on what might have been a typical day for a city high school boy who spent last summer helping out on a farm.

The sun isn't up yet, but Paul and the other men are up and are doing the morning chores-milking, feeding the livestock, and getting the horses and tractor ready.

Paul wanted to make sure that he was dressed on time and ready to leave with the other men, so after the first day he sent back home for his alarm clock. The old roosters on the farm still hadn't learned that this was a war-time emergency and farm people were getting up before daybreak! Right after chores, and just about the time the lazy old roosters are beginning to crow lustily and announce the dawn, Paul and the other men are already on their way back to the house to wash up for breakfast.

The big stacks of flapjacks and the steaming plates of bacon and eggs find Paul with a bigger appetite for breakfast than he had ever had in

PAGE 56

Boys and girls who work on general farms will share the living room with the farm family.

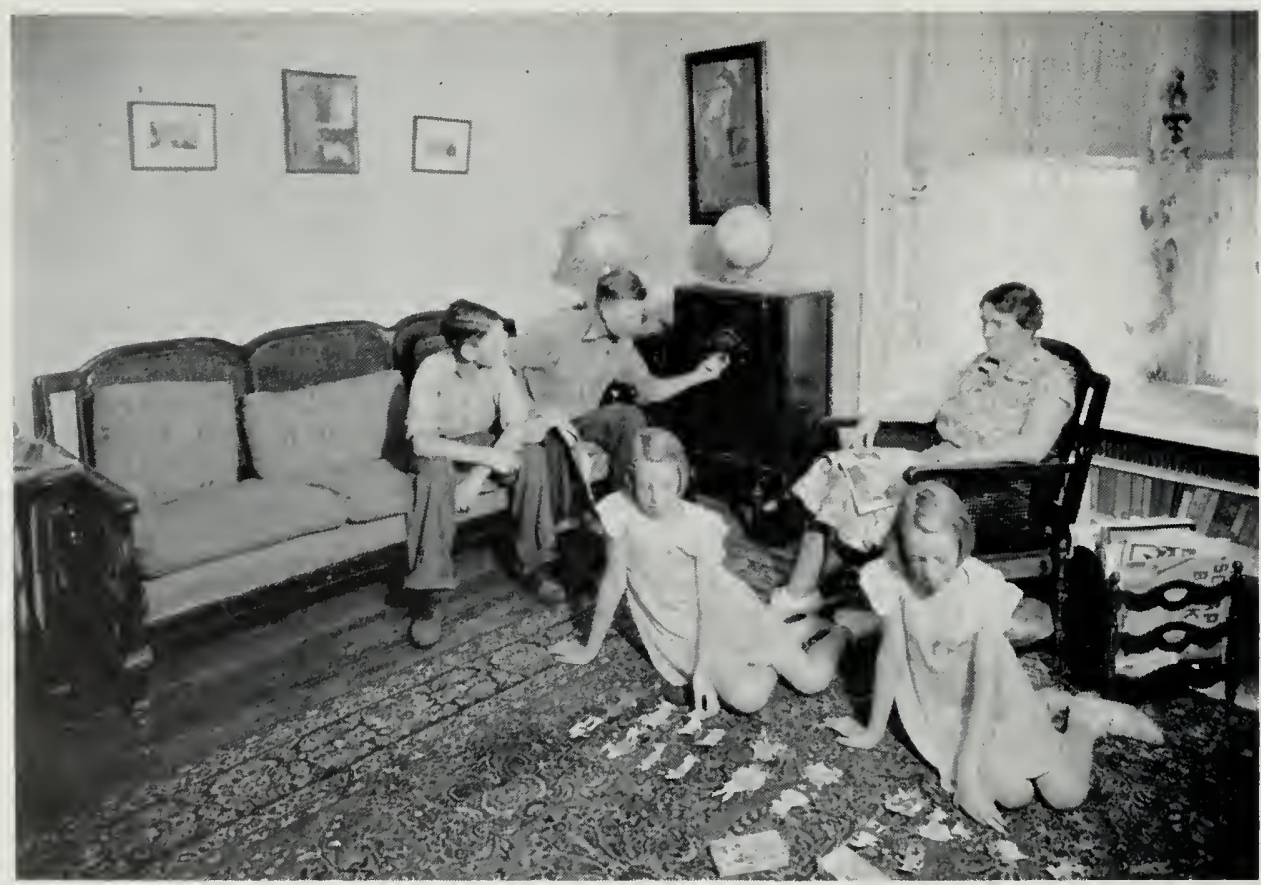




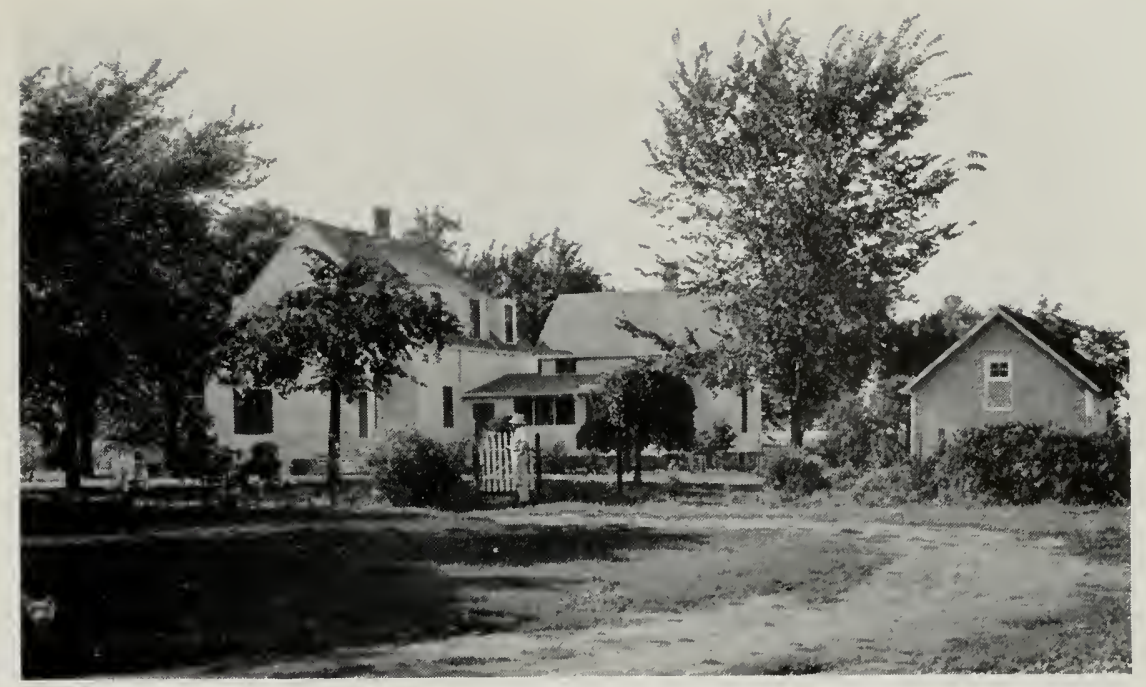

A shady lawn is a swell place to rest during the noon hour on a summer day.

the city. Eight hours of sleep and a half hour or more of work in the morning air has certainly done something.

Before leaving for work in the field, Paul makes his bed and puts his room in order. He wasn't used to doing this at home but it didn't take him long to see that farm women have many more tasks to worry about than his mother had in the city. Realizing this, he makes it a point to wipe his shoes before coming into the house, so as not to track up the floors.

He feels fine on the way to the field, for this is one of the nicest parts of the day. The sun has begun to rise and is spreading its colors across the sky, and he has a good breakfast under his belt.

Out in the field Paul gets further instructions about what he is to do. He listens carefully before carrying them out. He doesn't hesitate to ask questions, so he can be absolutely sure that he will do what is expected of him. He has learned, too, that he can get the hang of a lot of things by watching others and then doing them in the same way.

The second day he was on the farm, Paul had a good lesson about farm animals. He tried to milk one of the cows from the left side. The cow, however, had other ideas-she put her foot in the bucket and kicked Paul into the gutter. Mr. Brown, the farmer, explained that all cows are trained to be milked from the right side and that most of them resent any departure from this custom.

It was clear to Paul after this that he wouldn't stay on a farm long if he kept trying what he thought were "better ways." Those sore spots reminded him that he had better ask before trying out any new ideas. There usually were good reasons why Mr. Brown was using the methods he was.

From after sunup 'til close to noon, there is work to do with the men in the field. The sun is hot, and the work is heavy. Boy, does he sweat! This is real work! To avoid blisters, he has provided himself with work gloves to wear when pitching hay, scooping corn, or doing similar jobs. 
He also wears a wide-brimmed straw hat to protect his face and eyes from the blistering sun.

By dinner time the work in the field has left him dirty so he washes his face and hands in the basin outside the kitchen door and combs his hair. Since the other men will use the same basin, he uses plenty of soap and water to leave it clean for the next fellow.

Most farm families put all the food in large dishes on the table and then everybody "helps himself". So Paul takes normal portions of everything passed to him. There are corn bread muffins for clinner this noon. These happen to be something new to him. His mother didn't make them and he isn't quite sure whether he will like them. However, he knows it is courteous to eat whatever is put before him, so he tries one of them. Yum, are they good!! He asks for more and decides he will try everything once. His appreciation certainly pleases Mrs. Brown who prides herself on her good cooking.

Before he came to the country Paul was told not to leave any food on his plate when he finished eating, as far'm folks consider this wasteful. He smiles as he thinks of this now. It doesn't look as though he would have any trouble on that score-plenty of exercise, fresh air, and sunshine can make a fellow feel like a hungry bear.

Paul and the farmer's son Ed, a boy a few years younger than Paul and whose room Paul shares, have a lot to talk about at lunch. They listen to the older men, too. Paul enters into the conversation occasionally but is careful not to make a nuisance of himself by talking too much or by asking questions about things which are none of his concern.

After dinner the men rest for a short while before going out to their afternoon work.

Paul's work is different this afternoon. Mrs. Brown asks him to help her cultivate the garden. She leads the horse while Paul guides the cultivator, and later both use hoes to cut the weeds that grow in the rows

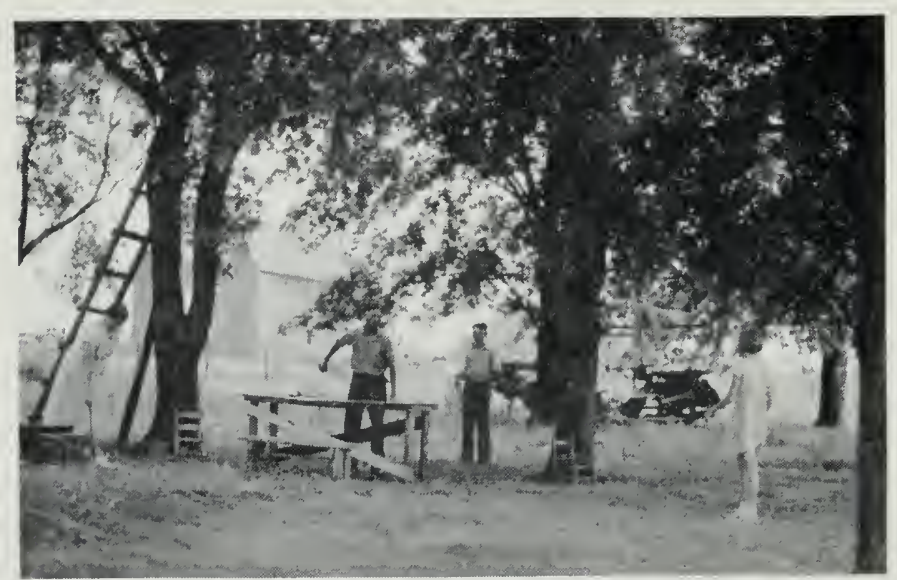

Most farm families find some time for play, and they usually have facil. ities available in their own yard. 
and were missed by the cultivator. Later in the afternoon he cleans out the poultry house, and fills the self-feeder and waterer for the hens. When the other men come in from the field he helps with the milking.

By 7 o'clock he has finished his work and he and Ed wash up and go into the house to read the paper before supper.

Paul is really doing a good job as a farm helper. Much of his success is due to his ability to fit into the life here as he finds it. He has been courteous and good natured. He has accepted country customs without criticism and has joined in the family life and games wholeheartedly. He has been considerate enough not to take privileges away from others, such as sitting in the only easy chair or monopolizing the evening paper or radio programs. He finds that he not only likes the men he works with but that he enjoys living with these people.

Since it happens to be Friday evening, the family decide to go to a movie and ask Paul if he wouldn't like to go too. He thanks them and says he would like to ride in with them, but since he has already made plans to go to a monthly meeting of a rural youth group with a highschool friend of his who works at a nearby farm, he makes an appointment to meet them when they are ready to start home. The boys have an unexpectedly good time at the meeting and Paul has much to talk about with the Browns on the way home.

They are all back at the farmhouse close to 10 o'clock, and by this time good and ready for bed. This is an hour later than usual for Paul, for he has usually been glad to "call it a day" at 9 o'clock. Eight good full hours of sleep are not too much if a fellow is to stand up to his next day's work. It hasn't been hard, since the first day or two, to leave those late city hours behind.

"Shucks," he mutters as he goes off to sleep, "it sure will take that old alarm clock to get me out of here in the morning."

\section{Your Summer on the Farm}

Living and working with farmers next summer will be an experience for you and will lead to a broader understanding and appreciation of the farmer and his family, their life and problems. Since about 26 million people in our country live on farms, it is decidedly worth while to know them in this way.

Join in the family social life when you are invited, and also take part in the community activities. You will probably have an opportunity to attend the church of your choice if there is one in the community or you may wish to go to the one attended by the farmer and his family.

There will likely be a $4-\mathrm{H}$ club or a chapter of Future Farmers of America in the neighborhood and when you are invited to attend their meetings do so as you will find them both interesting and instructive. The 4-H clubs have a project known as the "Victory Service Project" which is especially designed for boys from the city who are working on farms during the summer months. You can therefore become a regularly 
enrolled $4 \mathrm{H}$ member if you desire. You will discover that farm boys and girls take some time from work for baseball, swimming, or other outdoor sports, and you will be expected to join in these activities.

Before taking a job on a farm, have a thorough physical examination; be sure that you are fit and have no contagious disease.

Break into the work gradually, and do not overwork the first day. It will probably take you all of two weeks to get used to farm work. Your muscles will be stiff at first, especially during the first three days.

If you have lived in the city most of your life, you may find that a summer spent on a farm is a welcome change from city life. There may be times when your patience will be tried and your pride may be hurt, but you should be able to master your feelings. You will enjoy the large expanse of countryside, the fresh air, a new experience, and will have the satisfaction that comes with having done a real day's work, day in and day out. Farm work will develop your muscles, prepare you for athletic activities, and thus help build the kind of a body you will need for the rest of your life. Finally, your contribution to our war effort will be truly significant.

The farm family starts out for church on Sunday morning. If you work on a farm during the vacation period you will probably have a chance to attend church if you wish.

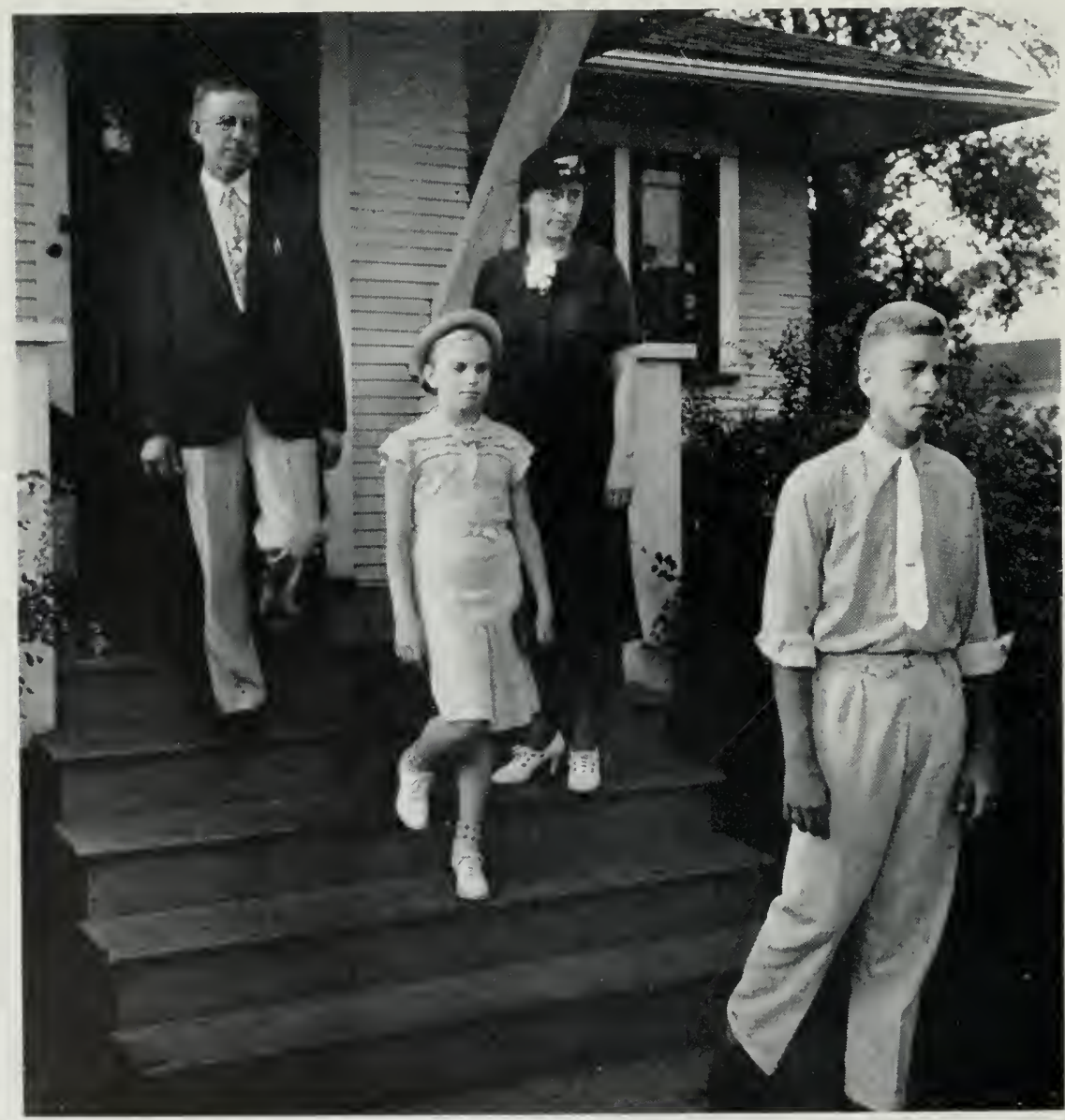




\section{ACKNOWLEDGMENT}

The publishers wish to express their appreciation to the following for use of the pictures in this publication:

University of Illinois, College of Agriculture, Urbana, Illinois

J. C. Allen and Son, West LaFayette, Indiana

International Harvester Company, Chicago, Illinois

John Deere Implement Company, Moline, Illinois

J. I. Case Company, Racine, Wisconsin

Caterpillar Tractor Company, Peoria, Illinois 


\section{sis \\ Contents}

Why City Boys and Girls Are Needed on Farms in 1943......... 6

Your Part in the War Effort................... 6

Agriculture-A National Industry .................. 6

Agriculture-An Essential War Industry ............... 6

The Farm Labor Situation. ................... 7

A Challenge to the City Youth of America............. 7

1. Work, Wages, and Living Conditions................. 8

The Nature of Farm Work..................... 8

Wages and Living Conditions. . . . . . . . . . . . . . . 10

There's a Place for the Girls, Too. . . . . . . . . . . . . . . . . . . 10

A Contribution to War Effort and Personal Development........ 11

2. Preparing and Planning for Farm Work. . . . . . . . . . . . 12

Start Making Plans Now. . . . . . . . . . . . . . . . . . . . 12

Personal Preparation-Physical and Mental............... 13

Learn by Visiting. ........................... 13

Placement Plans ......................... 14

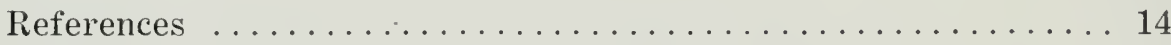

3. Dairy Cattle-Responsibilities for Feeding and Milking Them .... 15

Cows Are Sensitive Animals . . . . . . . . . . . . . . . . . . 15

Terms You Need to Know......................... 16

Care of a Dairy Herd......................... 17

High Production Is Your Challenge................. 20

4. Livestock-Care and Handling of Horses, Swine, Sheep, Poultry, and Beef Cattle............................ 21

Think of Animals as Friends..................... 21

Caring for and Handling Horses................... 21

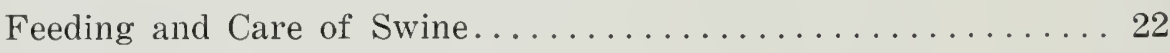

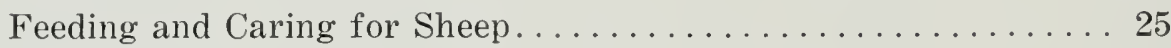

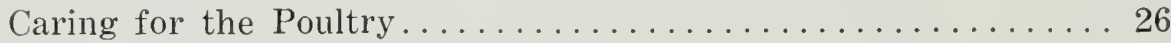

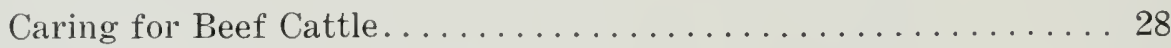

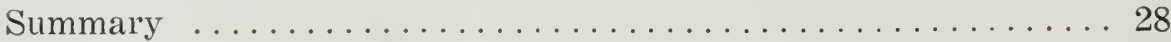

5. Crop Production-Your Responsibilities................ 29

Crop Production Is Basic to All Agriculture . . . . . . . . . . . 29

Crops Raised on the Farm ....................... 29

Your Jobs in Crop Production ................... . 31 


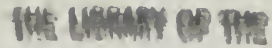 \\ SFP 251949

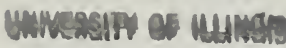 \\ Contents}

Page

6. Farm Equipment and Buildings................. 36

Learn to Identify . . . . . . . . . . . . . . . . . . 36

Small Tools . . . . . . . . . . . . . . . . . . . . . 37

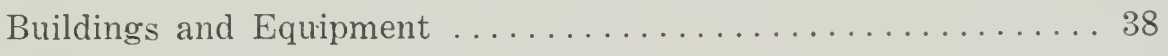

Miscellaneous Equipment ..................... 39

Your Opportunities and Responsibilities ............... 39

7. Operating Farm Machinery-Your Responsibilities........... 40

Kinds of Farm Machinery. . . . . . . . . . . . . . . . . 40

Farm Machinery and Wartime Production .............. 42

8. Special Types of Work and Odd Jobs on the Farm............ 44

Fruit, Vegetables and Canning Crops ................. 44

Commercial Vegetable Farms..................44

Know Your Vegetables ..................... 45

Nature of the Work ...................4 45

Commercial Fruit Farms ................. 46

Cannery Crops ...................... 47

Living Conditions on Specialized Farms ........... 47

Odd Jobs You May Be Asked to do.................... 48

Many Kinds of Odd Jobs on General Farms ............ 48

Odd Jobs About the Farmstead . . . . . . . . . . . . 48

Odd Jobs About the Farm .................. 49

Odd Jobs Essential to Farm Success . . . . . . . . . . . . 49

9. Safety Measures ....................... 50

We Can't Afford Accidents ................... 50

There Are Many Farm Hazards . . . . . . . . . . . . . . . . 50

Types of Farm Accidents . . . . . . . . . . . . . . . . . . 51

Accidents in the Home ..................... 53

Danger of Fires . . . . . . . . . . . . . . . . . . . 53

Safety Precautions ..................... 54

10. A Day on a Farm ...................... 56

Farm Life Is More Than Just Work . . . . . . . . . . . . . 56

Your Summer on the Farm .................... 59 


\section{To the High School Boys and Girls of Illinois} All fighting men recognize the truth of this statement.

It is not hard to understand, either, why a nation that has food to offer the hungry people of the world will be able to influence the direction which peace will take.

Secretary Wickard has marshalled these thoughts into one sentence: FOOD WILL WIN THE WAR AND WRITE THE PEACE.

If it is true that food may be the most critical factor in winning the war and in establishing a just and lasting peace when it is over, it is just as true that lack of it can help to lose the war and postpone indefinitely our obtaining the kind of peace we, as free Americans, can tolerate. That is why farm service in 1943 by those below military age will mean real service to our country and the cause we fight for.
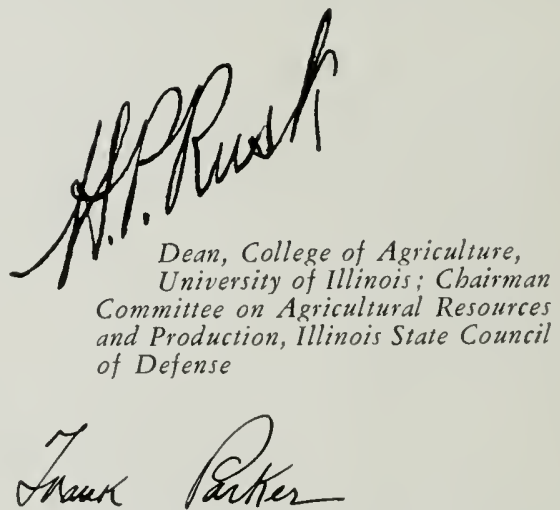

Major General; Executive Director, Illinois State Council of Defense 